\title{
Strain Rate-Dependent Constitutive and Low Stress Triaxiality Fracture Behavior Investigation of 6005 Al Alloy
}

\author{
Yong Peng $\mathbb{D}^{1,2,3}$ Xuanzhen Chen, ${ }^{1,2,3}$ Shan Peng, ${ }^{1,4}$ Chao Chen ${ }^{1},{ }^{5}$ Jiahao Li, ${ }^{1,6}$ \\ and Guowei Liu $^{1,2,3}$ \\ ${ }^{1}$ School of Traffic and Transportation Engineering, Central South University, Changsha 410075, China \\ ${ }^{2}$ Key Laboratory of Traffic Safety on Track, Central South University, Ministry of Education, Changsha 410075, China \\ ${ }^{3}$ National and Local Joint Engineering Research Center of Safety Technology for Rail Vehicle, Changsha 410075, China \\ ${ }^{4}$ Smart Transport Key Laboratory of Hunan Province, Changsha 410075, China \\ ${ }^{5}$ Hunan Industry Polytechnic, Changsha 410208, China \\ ${ }^{6}$ Joint International Research Laboratory of Key Technology for Rail Traffic Safety, Changsha 410075, China
}

Correspondence should be addressed to Chao Chen; hngyzycc@163.com

Received 19 June 2017; Revised 20 October 2017; Accepted 24 January 2018; Published 3 May 2018

Academic Editor: Luigi Nicolais

Copyright (c) 2018 Yong Peng et al. This is an open access article distributed under the Creative Commons Attribution License, which permits unrestricted use, distribution, and reproduction in any medium, provided the original work is properly cited.

In order to study the dynamic and fracture behavior of 6005 aluminum alloy at different strain rates and stress states, various tests (tensile tests at different strain rates and tensile shearing tests at five stress states) are conducted by Mechanical Testing and Simulation (MTS) and split-Hopkinson tension bar (SHTB). Numerical simulations based on the finite element method (FEM) are performed with ABAQUS/Standard to obtain the actual stress triaxialities and equivalent plastic strain to fracture. The results of tensile tests for $6005 \mathrm{Al}$ show obvious rate dependence on strain rates. The results obtained from simulations indicate the feature of nonmonotonicity between the strain to fracture and stress triaxiality. The equivalent plastic strain reduces to a minimum value and then increases in the stress triaxiality range from 0.04 to 0.30 . A simplified Johnson-Cook (JC) constitutive model is proposed to depict the relationship between the flow stress and strain rate. What is more, the strain-rate factor is modified using a quadratic polynomial regression model, in which it is considered to vary with the strain and strain rates. A fracture criterion is also proposed in a low stress triaxiality range from 0.04 to 0.369 . Error analysis for the modified JC model indicates that the model exhibits higher accuracy than the original one in predicting the flow stress at different strain rates. The fractography analysis indicates that the material has a typical ductile fracture mechanism including the shear fracture under pure shear and the dimple fracture under uniaxial tensile.

\section{Introduction}

$\mathrm{Al}-\mathrm{Mg}$-Si-Cu alloy, due to its excellent processing property and mechanical behavior with medium strength, superior corrosion resistance, and advanced welding performance, has been playing an important role in various industrial applications and scientific research [1]. It is crucial to ensure impact safety, while lightweight materials are extensively used to improve train speed [2-4]. A large number of studies [5-8] on the energy absorption components of the train show that the dynamic mechanical response of the material has a great influence on the performance of crash energy absorption. Previous studies [9-11] have investigated the dynamic response of different aluminum alloys. $6005 \mathrm{Al}$ alloy, as a common manufacturing material for high-speed train, attracted extensive attention. The effect of temperature on the micromechanics of ductile fracture and the continuous cooling precipitation, including temperature- and time-dependent precipitation behavior, were investigated in $[12,13]$. The influence of the age-hardening behavior and microstructural characterization of precipitates are also studied by electron microscopy [14].

To study the dynamic mechanical properties of materials, experimental studies, constitutive model, and numerical simulations have been developed under various loading conditions. Electronic testing machines and the splitHopkinson bar (SHPB) system have been used to investigate mechanical behavior under tension, compression, or other loading conditions [15-17]. Constitutive models 
including the physical model [18] and phenomenological model [19] have been developed to describe the flow stress and mechanical behavior of materials under various loading conditions. Numerical simulation, based on the finite element method (FEM), is always used to calculate the flow behavior of variety of materials under specified loading conditions [20,21]. The constitutive behavior model plays an important role in numerical simulation. The Johnson-Cook model [22], one of the most widely used phenomenological models, is used to describe the coupling factors of strain hardening, strain-rate hardening, and thermal. This model is also widely employed in numerical simulation because the five material constants can be easily acquired from the experimental data.

Ductility, considered as an important mechanical property, has been investigated on many materials $[10,23,24]$. Stress triaxiality, defined as the ratio of the hydrostatic stress and von Mises stress to depict the stress state of materials, is found to be an important factor that influences fracture strain greatly according to previous studies $[23,24]$. Several fracture models $[25,26]$ have been proposed to describe the dependency of fracture on the stress triaxiality. The JC fracture model [25] is a common model widely used in the commercial finite element code. However, the JC fracture model is not very accurate especially for the low triaxiality region. Bao and Wierzbicki (BW) [27] developed a more flexible fracture locus to reflect the fracture behavior in the fracture strain-triaxiality space. Wierzbicki et al. [28] compared seven representative criteria and found that the $\mathrm{X}-\mathrm{W}$ criterion was performing well in a wide triaxiality range. Even if the BW fracture locus is more practical than the JC one, it still does not consider the Lode angle effect. Recently, the importance of the two parameters, triaxiality and Lode angle, has been stressed for the ductile fracture of metals. The MMC is a modification of the original criterion whose description and derivation can be found in [29] and has been successfully used by Gilioli et al. [30] to study the ballistic impact failure of aluminum 6061-T6. Previous studies $[10,11,24]$ mostly focus on high triaxialities, which means that the material is under axial tension loading. The fracture behavior of $6005 \mathrm{Al}$ alloy under the tension and shearing loading would be studied.

In this paper, various loading conditions are set to obtain the dynamic behavior of $6005 \mathrm{Al}$ alloy. Not only the strainrate effect would be investigated through a series of experiments at different strain rates using the MTS and SHTB testing systems, but also the mechanical behavior under the combined force with tension and shearing was studied. There are several strain rates including quasi-static and dynamic $\left(10^{-3} \mathrm{~s}^{-1}, 10^{-2} \mathrm{~s}^{-1}, 10^{-1} \mathrm{~s}^{-1}, 700 \mathrm{~s}^{-1}, 1100 \mathrm{~s}^{-1}\right.$, and $\left.3300 \mathrm{~s}^{-1}\right)$. To investigate the fracture strain and ultimate strength of the material under the combined force with tension and shearing, tensile shearing tests under the different angles $\left(0^{\circ}, 30^{\circ}, 45^{\circ}, 60^{\circ}\right.$, and $90^{\circ}$, resp.) are performed. Furthermore, a modified Johnson-Cook constitutive model would be obtained to describe the dynamic behavior of 6005 $\mathrm{Al}$ alloy. Model predictions would be compared with the testing data. Finally, a fracture criterion would be proposed to describe the relationship between fracture strain and stress triaxiality at the stress state of low triaxialities.

\section{Methods}

2.1. Materials and Experiments. The present study has been carried out on $6005 \mathrm{Al}$ alloy. The chemical composition of the material is listed in Table 1. Two groups of experiments are set to study the mechanical property. They are tensile tests at various strain rates and tensile shearing tests of double-notch specimens. Three repeated tests under the same condition are carried out to ensure the accuracy and reliability of results, especially for dynamic loading tests.

2.1.1. Low Strain Rate Tensile Tests. To more reasonably study the mechanical behavior of $6005 \mathrm{Al}$ alloy under the quasistatic and low strain-rate loading condition, tension tests based on four strain rates (from $10^{-4} \mathrm{~s}^{-1}$ to $10^{-1} \mathrm{~s}^{-1}$ ) are adopted by the Mechanical Testing and Simulation (MTS) 647 hydraulic wedge grip. The maximum axial load ability of the machine is $200 \mathrm{kN}$. The tension specimens are used with the dimensions of $100 \mathrm{~mm}$ in the gauge length $L_{0}$ and $20 \mathrm{~mm}$ in the width of the cross section and $8 \mathrm{~mm}$ in the thickness of the cross section, as shown in Figure 1(a). The engineering stress $\sigma_{\mathrm{E}}$ and engineering strain $\varepsilon_{\mathrm{E}}$ can be expressed as follows:

$$
\begin{gathered}
\sigma_{\mathrm{E}}=\frac{F}{A_{0}}, \\
\varepsilon_{\mathrm{E}}=\frac{\Delta L}{L_{0}},
\end{gathered}
$$

where $A_{0}$ is the cross section area of the specimens. $F$ and $\Delta L$ are the tensile load and the elongation of the specimens, respectively. Furthermore, the true stress $\sigma_{\mathrm{T}}$ and true strain $\varepsilon_{\mathrm{T}}$ are obtained by the following equations [25]:

$$
\begin{aligned}
& \sigma_{\mathrm{T}}=\sigma_{\mathrm{E}}\left(1+\varepsilon_{\mathrm{E}}\right), \\
& \varepsilon_{\mathrm{T}}=\ln \left(1+\varepsilon_{\mathrm{E}}\right) .
\end{aligned}
$$

Note that (2) is inapplicable after the onset of necking. Figure 1(b) shows the specimen fixed in the MTS. Three repeated tests are conducted to ensure the repeatability.

2.1.2. SHTB Tests. SHTB test system is used to study the dynamic behavior of $6005 \mathrm{Al}$ alloy. The striker of SHTB is $20 \mathrm{~mm}$ in diameter and $500 \mathrm{~mm}$ in length. The incident bar is $20 \mathrm{~mm}$ in diameter and $3300 \mathrm{~mm}$ in length, while the transmitted bar is $20 \mathrm{~mm}$ in diameter and $1500 \mathrm{~mm}$ in length. To obtain a good signal of the strain and signal-to-interference ratio, both bars are made of LY12 $\mathrm{Al}$ alloy with ultrahigh hardness. The bullet, promoted by the launching system with high-pressure gas, impacts the flange of the incident bar. Then, a tensile loading wave generated through the incident bar. A strain gauge, affixed to the surface of the incident bar, records the incident signal and the reflected signal, while another one affixed to the surface of the transmitted bar records the transmission signal. All of signals simplified through a high dynamic strain meter are stored and recorded by an oscilloscope. Finally, a computer deals with the strain signals. Figure 2 shows the experimental device of the SHTB system.

Based on the hypothesis of the one-dimensional stress wave and strain and stress axial uniformity, the expression of 
TABLE 1: The chemical composition of $6005 \mathrm{Al}$ alloy.

\begin{tabular}{lccccccccc}
\hline Chemical element & $\mathrm{Si}$ & $\mathrm{Fe}$ & $\mathrm{Cu}$ & $\mathrm{Mn}$ & $\mathrm{Mg}$ & $\mathrm{Cr}$ & $\mathrm{Zn}$ & $\mathrm{Ti}$ & $\mathrm{Al}$ \\
\hline Wt.\% & $0.5 \sim 0.9$ & 0.35 & 0.3 & 0.5 & $0.4 \sim 0.7$ & 0.3 & 0.2 & 0.1 & Balanced \\
\hline
\end{tabular}
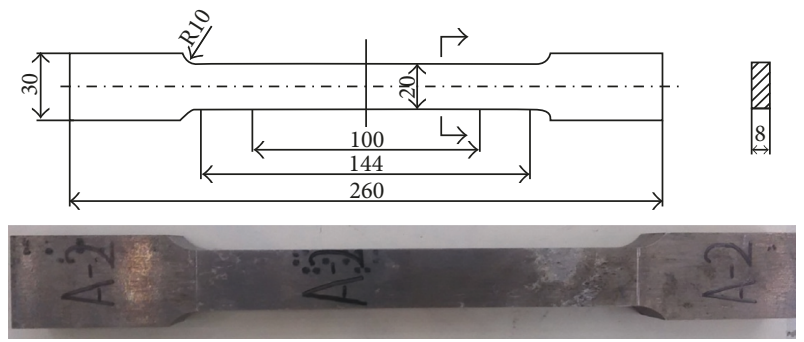

(a)

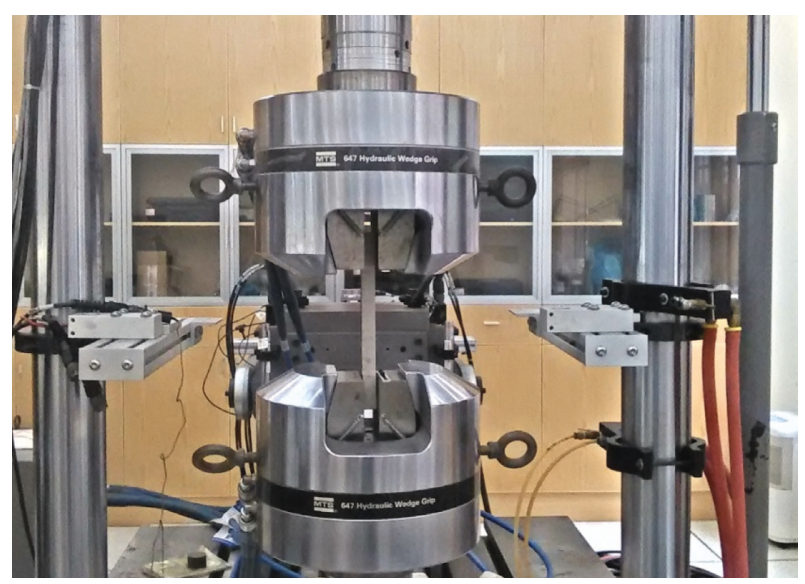

(b)

FIGURE 1: (a) Specimen for the conventional tension test; (b) MTS 647 hydraulic wedge grip used for the conventional tension test.

engineering stress, engineering strain, and strain rate is calculated by the following equations:

$$
\begin{aligned}
\sigma_{\mathrm{e}}(t) & =\frac{E A}{A_{S}} \varepsilon_{t}(t), \\
\varepsilon_{\mathrm{e}}(t) & =-\frac{2 C_{0}}{L} \int_{0}^{t} \varepsilon_{\mathrm{r}}(t) d t, \\
\dot{\varepsilon}(t) & =-\frac{2 C_{0}}{L} \varepsilon_{\mathrm{r}}(t),
\end{aligned}
$$

where $E$ is the elastic modulus of the incident bar. $A$ and $A_{\mathrm{S}}$ are the cross section areas of the incident bar and specimens, respectively. $C_{0}$ is the stress wave speed and $L$ is the gauge length of the specimens. $\varepsilon_{\mathrm{t}}(t)$ and $\varepsilon_{\mathrm{r}}(t)$ are the signals of the transmission wave and reflection wave. $\dot{\varepsilon}(t)$ is the strain rate. The true stress and true strain of the dynamic tensile experiment can also be obtained by (2).

In this study, three different strain rates, that is, $700 \mathrm{~s}^{-1}$, $1100 \mathrm{~s}^{-1}$, and $3300 \mathrm{~s}^{-1}$, are conducted to research the dynamic behavior at high strain rates. Three repeat measurements are performed in each test in order to improve the accuracy

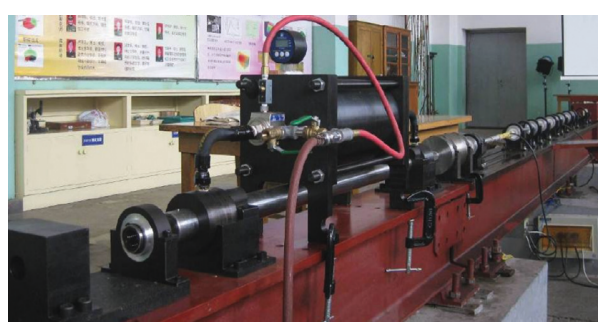

(a)

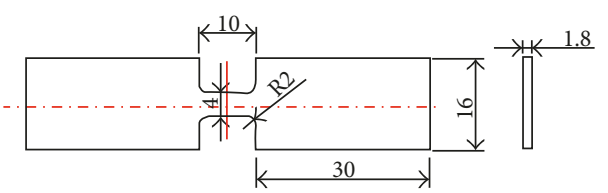

(b)

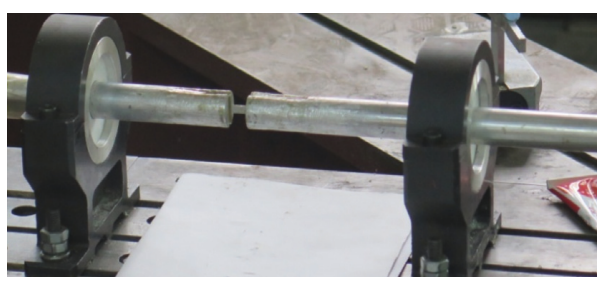

(c)

Figure 2: (a) Split-Hopkins tensile bar (SHTB) testing system; (b) specimen for the tension test under high strain rate; (c) specimen fixed in the SHTB system.

of results. The specimen is fixed in the SHTB as shown in Figure 2(c).

2.1.3. Tensile Shearing Tests. Tensile shearing tests have been carried out to investigate the relationship between stress triaxiality, double-notch specimens with different stress triaxialities are machined. The specimens are similarly used with the dimensions of $60 \mathrm{~mm}$ in overall length, $5 \mathrm{~mm}$ in gauge length, $3 \mathrm{~mm}$ in notch length, $20 \mathrm{~mm}$ in width, and $7 \mathrm{~mm}$ in thickness. The angles between loading direction and the bearing cross section between two notches, denoted as $\alpha$, are designed as $0^{\circ}, 30^{\circ}, 45^{\circ}, 60^{\circ}$, and $90^{\circ}$, respectively. Figure 3 shows the specimens of shearing tests. The tensile shearing tests of $0^{\circ}$ specimens can be regarded as pure shear tests, while other tests are under the combined action of tension and shearing. For these tests, the normal stress and shearing stress can be obtained through the following equations:

$$
\begin{gathered}
\sigma=\frac{F \sin \alpha}{A_{\min }}, \\
\tau=\frac{F \cos \alpha}{A_{\min }},
\end{gathered}
$$



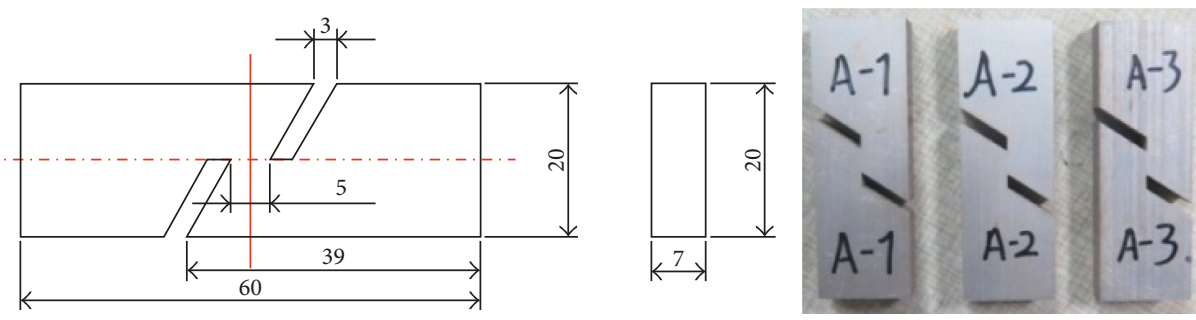

(a)
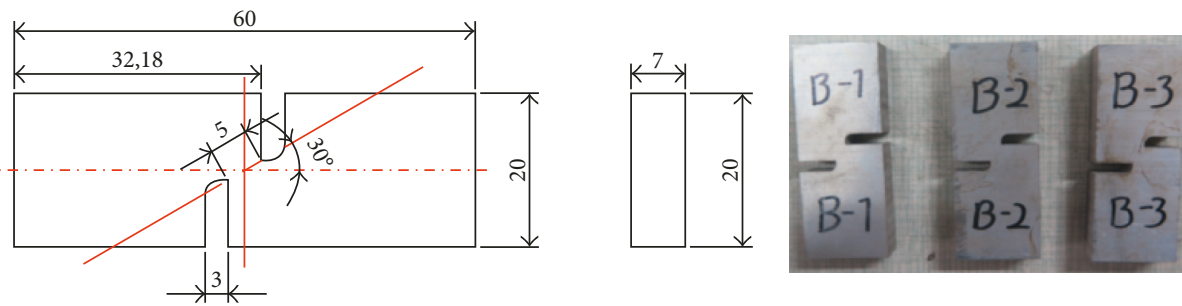

(b)
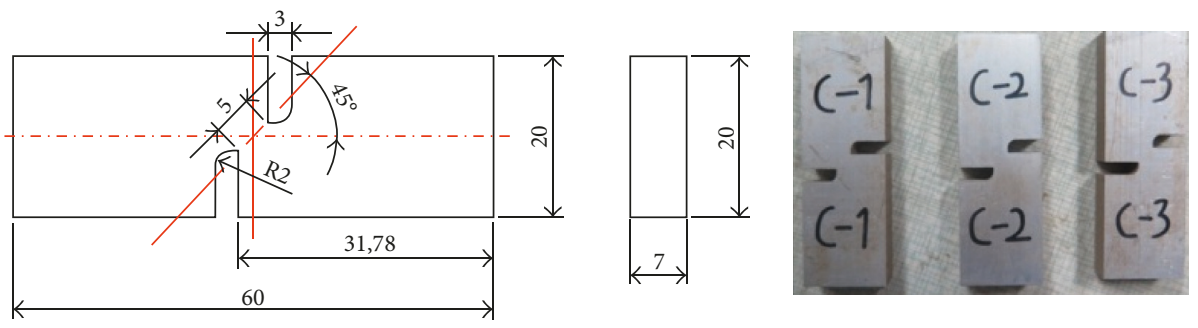

(c)
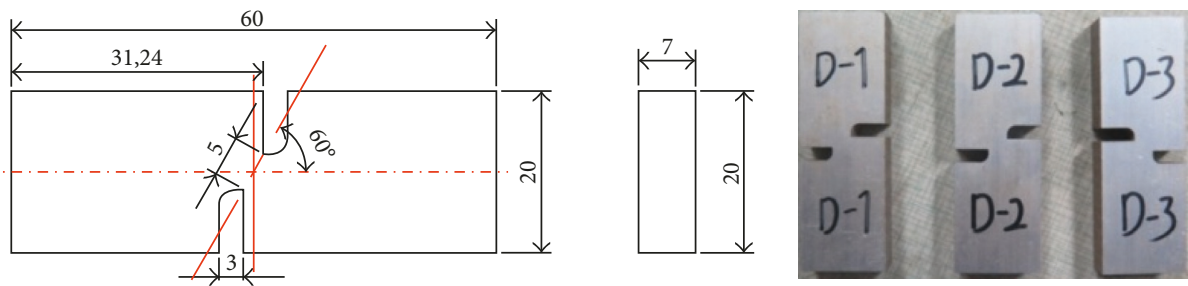

(d)
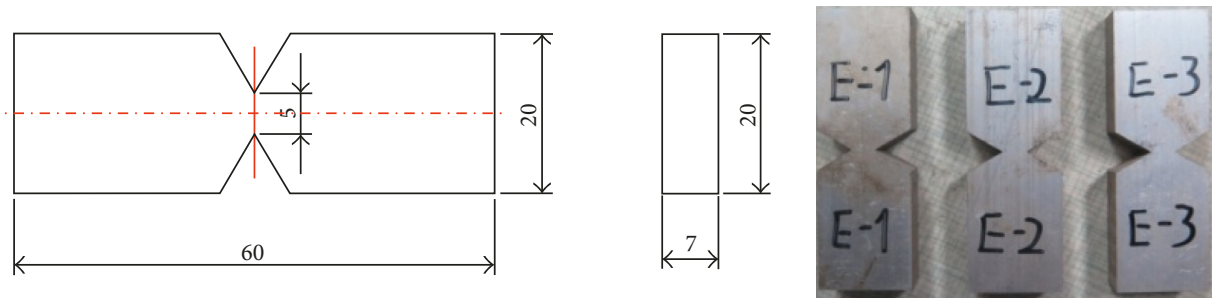

(e)

Figure 3: Specimens with different notch degrees: (a) $0^{\circ}$, (b) $30^{\circ}$, (c) $45^{\circ}$, (d) $60^{\circ}$, and (e) $90^{\circ}$ for tensile shearing tests.

where $A_{\text {min }}$ is the bearing area of the notched specimens given as follows:

$$
A_{\min }=t l
$$

where $t$ and $l$ are the thickness and length of the bearing cross section between two notches. For the plane stress state, principal stresses can be calculated with the following equation:

$$
\left.\begin{array}{c}
\sigma_{\max } \\
\sigma_{\min }
\end{array}\right\}=\frac{\sigma}{2} \pm \sqrt{\frac{\sigma^{2}}{4}+\tau^{2}}
$$

The stress triaxiality is defined as

$$
\sigma^{*}=\frac{\sigma_{\mathrm{h}}}{\sigma_{\mathrm{m}}}=\frac{\left(\sigma_{1}+\sigma_{2}+\sigma_{3}\right) / 3}{\sqrt{\left(\left(\sigma_{1}-\sigma_{2}\right)^{2}+\left(\sigma_{2}-\sigma_{3}\right)^{2}+\left(\sigma_{3}-\sigma_{1}\right)^{2}\right) / 2}},
$$


TABle 2: The theoretical initial stress triaxialities of different specimens.

\begin{tabular}{lccccc}
\hline Angle $\alpha$ & $0^{\circ}$ & $30^{\circ}$ & $45^{\circ}$ & $60^{\circ}$ & $90^{\circ}$ \\
\hline$\sigma^{*}$ & 0 & 0.105 & 0.167 & 0.236 & 0.33 \\
\hline
\end{tabular}

TABle 3: Values of material parameters for $6005 \mathrm{Al}$ alloy.

\begin{tabular}{lcccc}
\hline Parameter & $\rho\left(\mathrm{g} / \mathrm{cm}^{3}\right)$ & $C_{p}\left(\mathrm{~J} \cdot(\mathrm{K} \cdot \mathrm{g})^{-1}\right)$ & $\chi$ & $T_{\mathrm{m}}(\mathrm{K})$ \\
\hline Value & 2.71 & 0.96 & 0.9 & 933 \\
\hline
\end{tabular}

where $\sigma_{\mathrm{h}}$ is the hydrostatic stress, $\sigma_{\mathrm{m}}$ is the von Mises equivalent stress, and $\sigma_{1}, \sigma_{2}$, and $\sigma_{3}$ represent three principal stresses. According to (4)-(7), the stress triaxiality can be rewritten as

$$
\sigma^{*}=\frac{\sin \alpha}{3 \sqrt{\sin ^{2} \alpha+3 \cos ^{2} \alpha}}
$$

The initial stress triaxialities of different specimens are listed in Table 2. It can be found that the stress triaxiality increases from 0 to 0.33 with the increase of $\alpha$. These tests are conducted by MTS, and the loading speed is $1 \mathrm{~mm} / \mathrm{min}$.

2.2. Constitutive Model. For tensile loading, to reflect the relationship between strain, stress, strain-rate hardening, and ambient temperature, the Johnson-Cook model [22], one of the widely used constitutive models, is commonly applied to describe the flow behavior, which is shown as follows:

$$
\sigma=\left(A+B \varepsilon^{n}\right)\left(1+C \ln \dot{\varepsilon}^{*}\right)\left(1-\left(T^{*}\right)^{m}\right),
$$

where $\sigma$ and $\varepsilon$ are the stress and equivalent plastic strain, respectively. $A$ is the yield stress of the material. $B$ and $n$ are the parameters of strain hardening. $C$ is the strain-rate hardening parameter, determined by the material. $\dot{\varepsilon}^{*}=\dot{\varepsilon} / \dot{\varepsilon}_{0}$ is the dimensionless plastic strain rate, where $\dot{\varepsilon}$ is the strain rate and $\dot{\varepsilon}_{0}$ is the reference strain rate. $T^{*}=\left(T-T_{\mathrm{r}}\right) /$ $\left(T_{\mathrm{m}}-T_{\mathrm{r}}\right)$ is the dimensionless temperature indicating the thermal softening effect, where $T_{\mathrm{r}}$ is the room temperature and $T_{\mathrm{m}}$ is the melting point of the material. During high strain-rate loading, specimens are reasonable to be assumed in adiabatic conditions. In this case, the rate of temperature change is calculated through

$$
\dot{T}=\chi \frac{\sigma \dot{\varepsilon}}{\rho C_{p}}
$$

where $\rho$ and $C_{p}$ and are the density and heat capacity of the material. $\chi$ is the conversion factor of work into heat. The temperature rise can be estimated using the following equation:

$$
\int_{T_{0}}^{T} \rho C_{p} d T=\chi \int_{0}^{\mathcal{E}_{\mathrm{e}}} \sigma d \varepsilon
$$

where $\varepsilon_{\mathrm{e}}$ is the strain corresponding to the maximum stress. $\rho$ and $C_{p}$ are assumed as constants, while $\chi$ is taken as 0.9 for

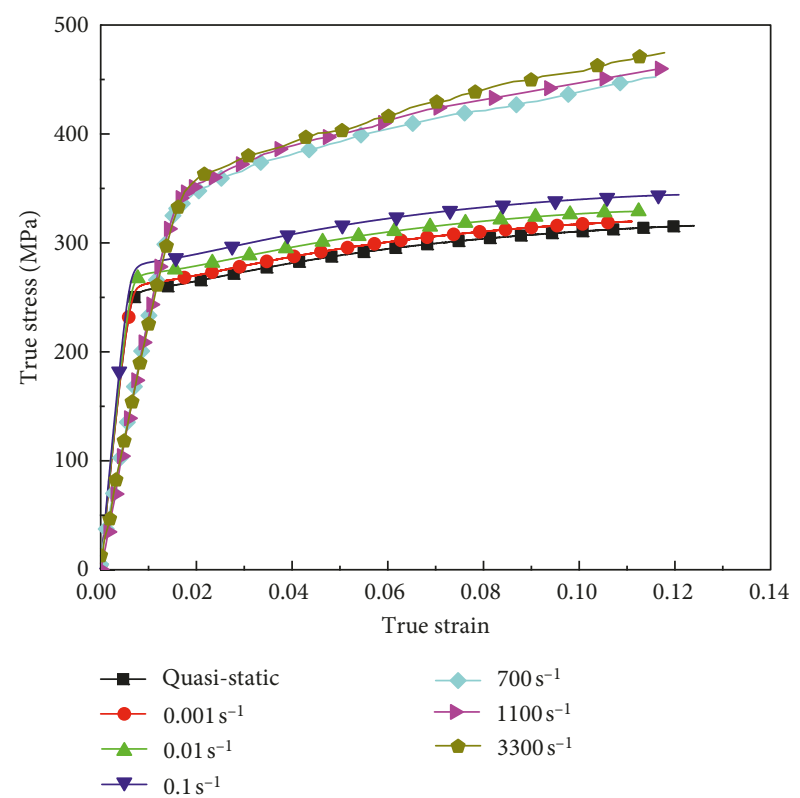

FIgURE 4: True strain-stress curves of $6005 \mathrm{Al}$ alloy at different strain rates.

metals [31]. The related parameters are given in Table 3. The equation can be rewritten as

$$
\Delta T=\frac{0.9}{\rho C_{p}} \int_{0}^{\varepsilon_{\mathrm{e}}} \sigma d \varepsilon
$$

All tensile tests in this study are conducted at room temperature. Furthermore, strain hardening and strain-rate hardening are only considered without the effect of temperature for low strain-rate tests. Therefore, the JC model can be simplified as the following equation:

$$
\sigma=\left(A+B \varepsilon^{n}\right)\left(1+C \ln \dot{\varepsilon}^{*}\right) .
$$

In this study, $10^{-4} \mathrm{~s}^{-1}$ is specified as the reference strain rate, that is, $\dot{\varepsilon}_{0}=10^{-4} \mathrm{~s}^{-1}$. The constitutive behavior model can be rewritten as

$$
\sigma=A+B \varepsilon^{n}
$$

Then, take logarithm on both sides of the equation, and the equation can be rewritten as

$$
\ln (\sigma-A)=\ln B+n \ln \varepsilon .
$$

Unknown parameters $A, B$, and $n$ can be determined with the least squares method. In $B$ and $n$ represent the intercept of the straight line and the slope of the straight line, respectively.

Next, to obtain the value of $C$, the equation can be transformed as follows:

$$
\frac{\sigma_{2}(\dot{\varepsilon})}{\sigma_{1}}-1=C \ln \dot{\varepsilon}^{*},
$$

where $\sigma_{1}=A+B \varepsilon^{n}, \sigma_{1}$ represents the stress of the material at $10^{-4} \mathrm{~s}^{-1}$ strain rate, and $\sigma_{2}(\dot{\varepsilon})$ represents the yield stress at a strain rate of $\dot{\varepsilon}$. 
TABLE 4: The yield and ultimate stresses under different strain rates for $6005 \mathrm{Al}$ alloy.

\begin{tabular}{|c|c|c|c|c|c|c|c|}
\hline Strain rate $\dot{\varepsilon}\left(\mathrm{s}^{-1}\right)$ & Quasi-static & 0.001 & 0.01 & 0.1 & 700 & 1100 & 3300 \\
\hline Yield stress $\sigma_{\mathrm{y}}(\mathrm{MPa})$ & 255.27 & 260.42 & 269.53 & 279.56 & 325.03 & 338.08 & 346.38 \\
\hline Ultimate stress $\sigma_{\mathrm{u}}(\mathrm{MPa})$ & 315.82 & 319.70 & 329.03 & 344.21 & 452.29 & 455.34 & 474.58 \\
\hline
\end{tabular}

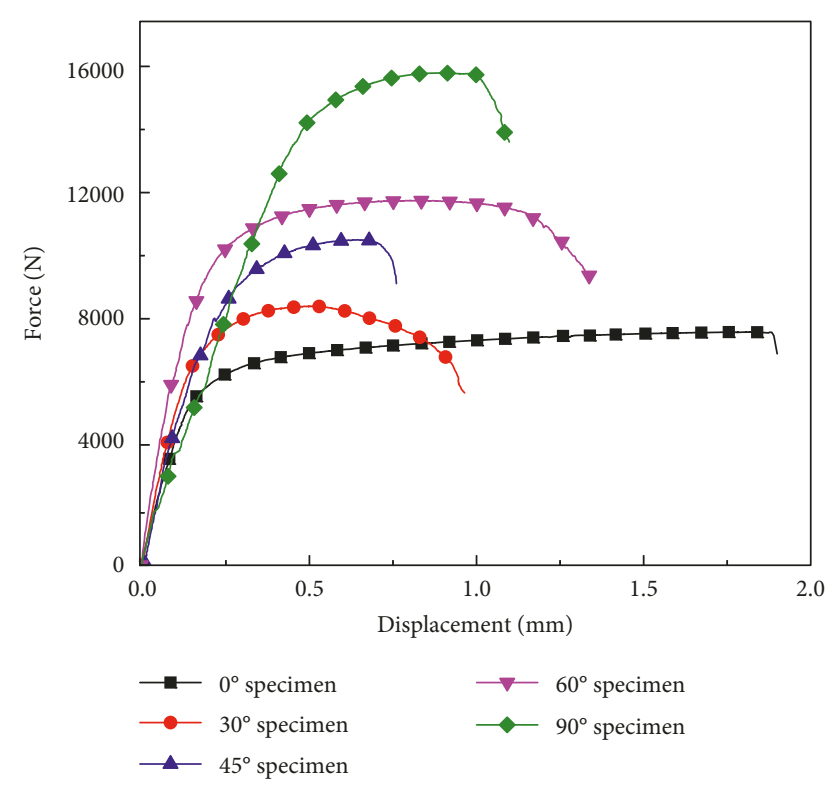

Figure 5: Experimental results for different specimens.

\section{Results}

3.1. Flow Stress at Different Strain Rates. The true stressstrain curves under different tensile strain rates before the onset of necking are plotted in Figure 4. The tension process can be generally divided into two stages: elastic stage and plastic stage. One thing to note about the difference of Young's modulus between low and high strain rates at the elastic stage is the fact that, during Hopkinson tensile tests, the stress wave in the specimen needs two or three reflections to achieve uniformity, resulting in the inhomogeneity of stress in the specimen. Therefore, the stress-strain relation at high strain rates is inaccurate. For the plastic stage, the strain hardening effect can be seen under each condition. A stronger strain hardening effect is observed at higher strain rates $\left(700 s^{-1}-3300 s^{-1}\right)$ in the plastic stage. In addition, a clear strain-rate hardening effect is observed when comparing curves of different strain rates. The yield strength and ultimate strength for $6005 \mathrm{Al}$ alloy under different strain rates are all listed in Table 3.

From Table 4, it can be seen that the yield stress and ultimate stress gradually increase when the strain rate increases. The yield stress experiences an increase of $35.7 \%$ from quasi-static to $3300 \mathrm{~s}^{-1}$, while the ultimate stress increases by $50.3 \%$. Evidently, $6005 \mathrm{Al}$ alloy is a material with great dependence on the strain rate.

3.2. Results of Tensile Shearing Tests. For this group of tests, the central cross section of specimens is under tension-shear combined loading, which is a complex stress state. The true
TAble 5: Parameters of the Johnson-Cook model of $6005 \mathrm{Al}$ alloy.

\begin{tabular}{lcccc}
\hline Parameter & $A(\mathrm{MPa})$ & $B(\mathrm{MPa})$ & $n$ & $C$ \\
\hline Value & 255.28 & 411.69 & 0.82 & 0.0186 \\
\hline
\end{tabular}

stress and true strain cannot be obtained directly due to the different deformation mode for each test. The experimental results are thus exhibited with the curves of force and displacement, as shown in Figure 5. As the comparison shows, the maximum tensile force for different specimens differs a lot. As the notch angle increases from $0^{\circ}$ to $90^{\circ}$, the maximum tensile force increases monotonously from $7718 \mathrm{~N}$ to $16301 \mathrm{~N}$ experiencing an increase of $111.21 \%$. The fracture displacements scatter from $0.76 \mathrm{~mm}$ to $1.9 \mathrm{~mm}$, and no clear correlation to notch angle is observed.

3.3. Material Parameter Identification. The experimental data of the quasi-static tensile are used to determine the three material constants $A, B$, and $n$, and the yield stress data at the strain rate range from quasi-static to $0.1 \mathrm{~s}^{-1}$ to determine $C$ of the simplified Johnson-Cook model. The temperature soft parameter $m$ can be obtained by comparing the results from experiments and the simplified JC model. The four parameters for $6005 \mathrm{Al}$ alloy at different strain rates can be obtained with the method mentioned in Section 2.2 as shown in Table 5. The relationship between $\ln (\sigma-A)$ and $\ln \varepsilon$ is shown in Figure 6.

To compare the predicted results from the JC constitutive model and experimented results, both of the two data groups are plotted in Figure 7. However, the values of yield stress at high strain rates are underestimated. Considering the temperature rise caused by the adiabatic process at high strain rates is limited ( $30 \mathrm{~K}$ calculated by $(9 \mathrm{~d})$ ), the temperature effect is neglected. It could be observed that the prediction agrees well with the experiments at the quasistatic strain rate, and with the increase of strain rate, the prediction deviates from experimented results increasingly. This deviation may be caused by neglecting the variations of the strain-rate coefficients. That is, the parameter $C$ in the JC model is supposed to be a variable instead of a constant. Apparently, the original JC constitutive model cannot depict the flow stress behavior at dynamic loading adequately. Therefore, it is necessary to modify the original JC constitutive model.

3.4. The Modification of the JC Constitutive Model. For the simplified JC constitutive model neglecting the temperature effect, flow stress is a function of strain and strain rate. The relationship between flow stress and $\ln \dot{\varepsilon}^{*}$ is considered as linear in the original JC model, which is an ideal case. Actually, the strain-rate coefficient may also correlate with strain. In other words, for a material under a certain strainrate loading, the strain-rate coefficient may vary with the 


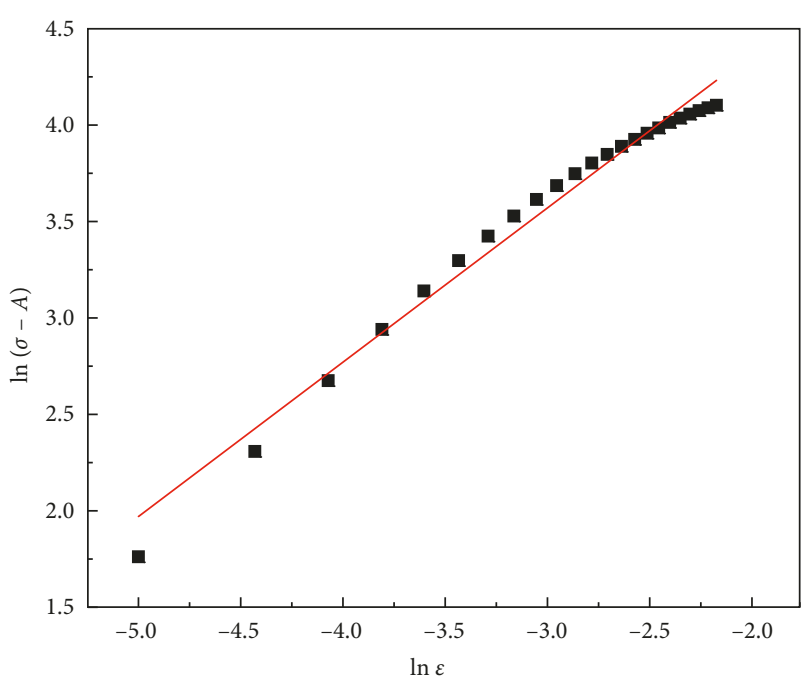

FIgURE 6: Relationship between $\ln (\sigma-A)$ and $\ln \varepsilon$.

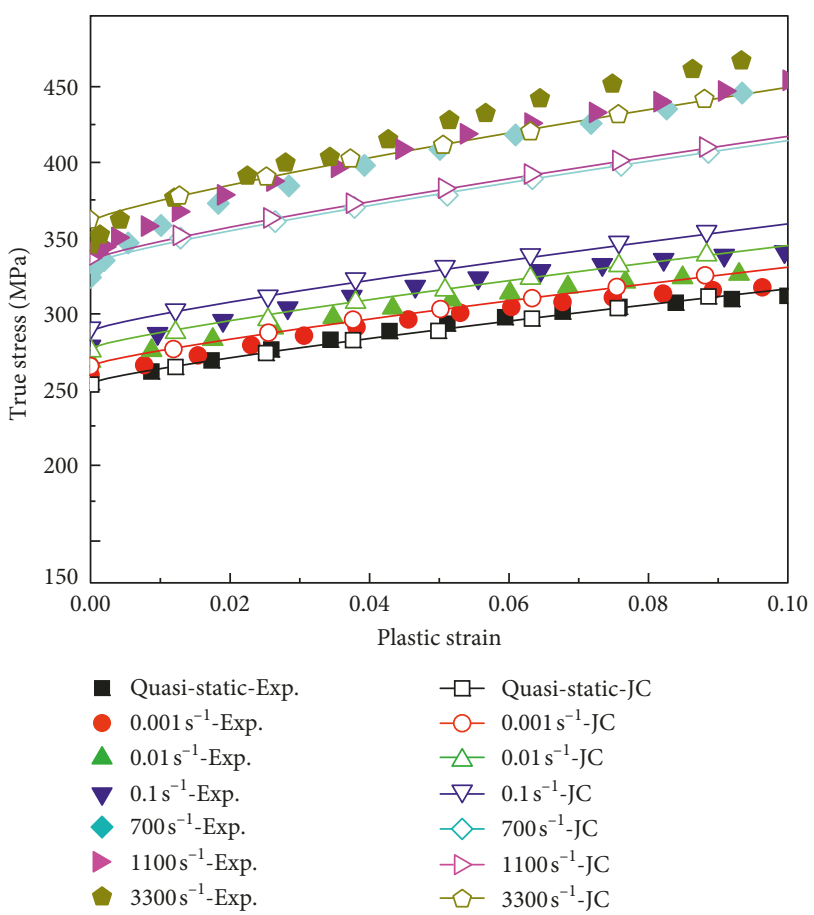

FIGURE 7: Comparison between predicted results of the JC model and experimental results at different strain rates.

development of plastic deformation. Figure 8 exhibits the relationship between the strain-rate coefficient and strain. On one hand, a nonlinear relationship can be found between $C$ and $\varepsilon$. On the other hand, for different strain rates, the relationship is different. A nonlinear relationship can be observed as well when it comes to $C$ and $\ln \dot{\varepsilon}^{*}$, as shown in Figure 9. Therefore, it can be assumed that $C$ is a function of strains and strain rates. The relationship is given as follows:

$$
C=f\left(\varepsilon, \ln \dot{\varepsilon}^{*}\right) .
$$

From Figures 8 and 9, considering the nonlinear relationship between $C$ and the two variables, $C$ can be

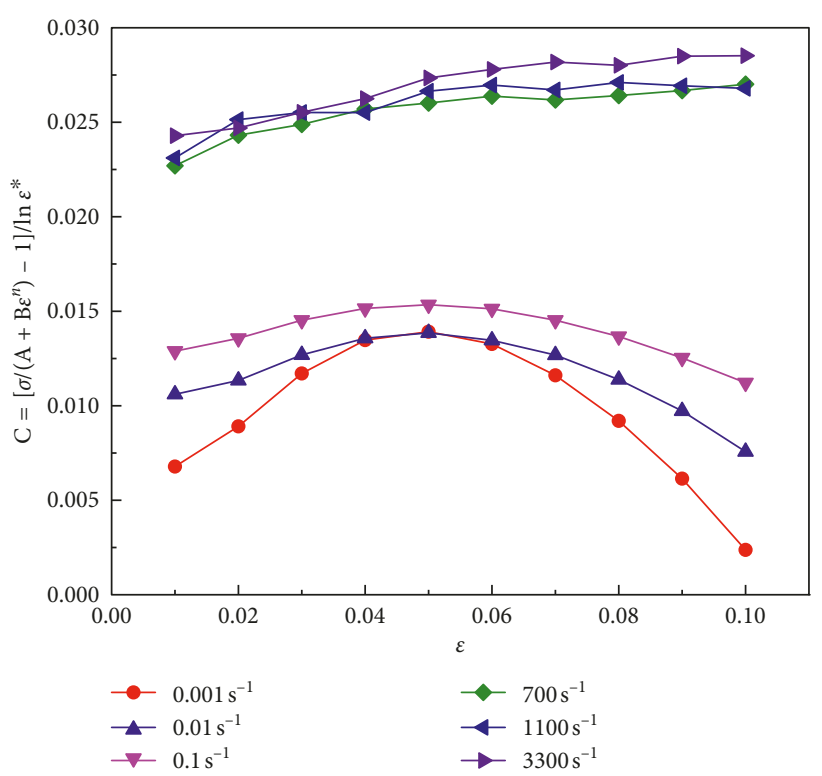

Figure 8: Relationship between $C$ and $\varepsilon$.

described as a binary quadratic polynomial of $\varepsilon$ and In $\dot{\varepsilon}^{*}$ independently. In addition, the interaction effect between the two variables should be taken into consideration. A quadratic polynomial regression model can thus be used to describe the relationship between $C$ and $\varepsilon$ and between $C$ and In $\dot{\varepsilon}^{*}$ shown as follows:

$$
C=C_{0}+C_{1} \varepsilon+C_{2} \varepsilon^{2}+C_{3} \ln \dot{\varepsilon}^{*}+C_{4}\left(\ln \dot{\varepsilon}^{*}\right)^{2}+C_{5} \varepsilon \ln \dot{\varepsilon}^{*},
$$

where $C_{0}-C_{5}$ are coefficients needed to be solved. The relationship between $C$ and the two independent variables can be described with a surface in the three-dimensional space coordinate system. The six coefficients can be obtained directly by nonlinear surface fitting (shown in Figure 10). The blue surface represents experimental data, and the red one is the fitting surface.

The parameters of the modified JC constitutive model of $6005 \mathrm{Al}$ alloy are listed in Table 6. Comparison between the predicted and experimented results is shown in Figure 11. Obviously, the modified JC model predicts the flow stress more accurately compared with the original JC model. It is indicated that the modification using the $C$ function is effective to depict the flow behavior of the investigated material.

3.5. FEA Modeling of Tensile Shearing Tests. In this paper, numerical simulations are used to obtain the actual initial stress triaxiality and equivalent plastic strain to fracture. ABAQUS/Standard, as a common FEA code, is employed to simulate tensile shearing tests. Five tensile shearing tests of different angle specimens are simulated. The material property is defined as elastic-plastic and isotropic hardening. The stressstrain data of the plastic stage from the quasi-static tensile test are input. The element type is the three-dimensional hexahedral element with reduced integration. The 3D finite element model meshes of specimens are all shown in Figure 12. The minimum size of elements is 0.2 . The nodes on one end of the $3 \mathrm{D}$ finite element model are fixed, while displacement 


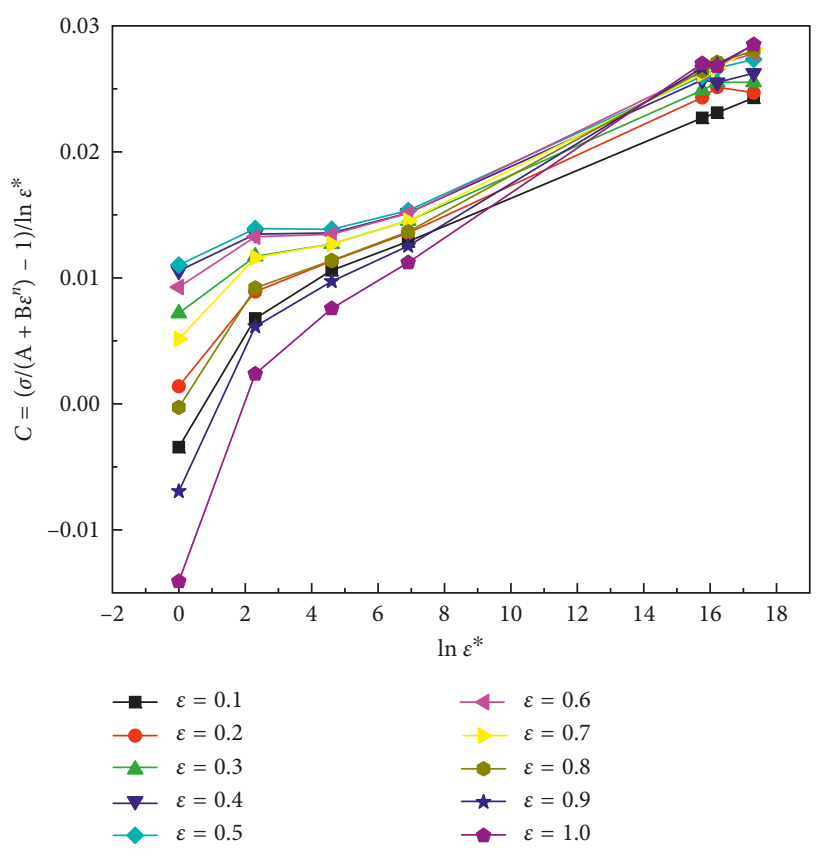

Figure 9: Relationship between $C$ and In $\dot{\varepsilon}^{*}$.

boundary conditions are imposed on the ones on the other end. It is worth stressing that fracture criterion is not applied in modeling for the reason that the numerical simulations are performed to validate the numerical analysis results.

Results obtained from the numerical simulations and experiments are compared in Figure 13. The two groups of force-displacement curves are in good agreement before the onset of fracture, as can be seen in Figure 13. Because no failure criterion is employed in the simulations, the simulations do not reflect the fracture behavior. However, due to the good agreement before the onset of fracture, it is still reliable to obtain the equivalent plastic strain to fracture and stress triaxiality from numerical simulations. The FEA model can thus be used to formulate the fracture strain.

3.6. Fracture Criterion for 6005 Al Alloy. In a certain triaxiality region, the coupling of the triaxiality and fracture strain constitutes a fracture criterion. The model built in Section 3.5 is used to obtain the equivalent plastic strain to fracture. By comparing the force-displacement curves of simulations and experiments, the fracture time step can be determined. The equivalent plastic strain at this time step is the fracture strain. It should be noted that the object to study is the critical elements where the fracture begins. The point is to determine the location where the fracture begins. It is observed from the finite element models that the maximum equivalent plastic strain at the fracture time step locates in the root of notches, which means that the fracture begins there. Figure 14 shows the distribution of equivalent plastic strain at the fracture time step in a typical numerical simulation.

In Section 2.1.3, a theoretical calculation method based on the assumption of the plane stress state for the initial stress triaxiality is proposed. However, specimens under tensile loading are actually in the three-dimensional stress state. Therefore, it is

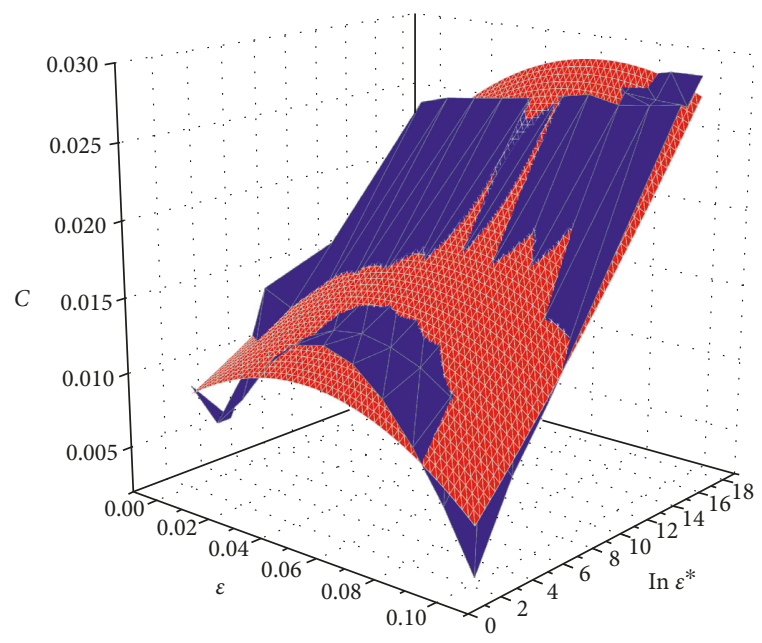

FIGURE 10: Nonlinear surface fitting of the quadratic polynomial regression model.

necessary to acquire the actual initial stress triaxiality from the numerical simulations. The two sets of initial stress triaxialities and corresponding fracture strains are listed in Table 7.

According to Table 7 , the actual initial stress triaxialities, within the range from 0.04 to 0.741 , are obviously greater than the theoretical values. It may be caused due to the threedimensional stress instead of the plane stress state in which the specimen is. The actual initial stress triaxialities coupled with equivalent plastic strains to fracture are plotted in Figure 15. Results indicate that the equivalent plastic strain to fracture presents nonmonotonic dependence on the initial stress triaxiality. In the stress triaxiality range from 0.04 to 0.369 , which is a low triaxiality level, when $\sigma^{*}$ increased, the fracture strain increases as well from 0.767 to 1.423 . A drop shows up as the stress triaxiality exceeds 0.369 , a relatively high triaxiality level. According to the study by Bao and Wierzbicki [23], for low triaxialities (0.04-0.369), a parabolic fit is found to be satisfactory. The fitting result is shown as (12). A plot of the equation is shown in Figure 16.

$$
\varepsilon_{p}^{f}=0.76 * \sigma^{* 2}-1.12 * \sigma^{*}+1.85 \text {. }
$$

\section{Discussion}

4.1. Evaluation of the Modified JC Model. In Section 3.2, a modified JC constitutive model has been proposed in which $C$ is considered to be relative to strain and strain rate. Previous studies [32, 33] have modified JC constitutive model for high-strength alloys by changing the form of the strain hardening factor and for AA6005-T6 by multiplying the strain-rate factor with a true stress. The method used in the present study has been successfully employed to modify the JC model for 7050-T745 aluminum alloy in [34].

To accurately evaluate the forecasting error of two constitutive models of 6005 aluminum alloy, three evaluating indices are investigated. They are the correlation coefficient, normalized mean bias value, and average absolute relative error denoted as $R$, $\mathrm{NMBE}$, and AARE, respectively, which are expressed as follows: 
TABLE 6: The material constants of the modified JC constitutive model of $6005 \mathrm{Al}$ alloy.

\begin{tabular}{lccccccccc}
\hline Parameter & $A(\mathrm{MPa})$ & $B(\mathrm{MPa})$ & $n$ & $C_{0}$ & $C_{1}$ & $C_{2}$ & $C_{3}$ & $C_{4}$ & $C_{5}$ \\
\hline Value & 255.3 & 411.7 & 0.8230 & 0.002238 & 0.1890 & 0.001622 & 0.007192 & -2.480 & $-3.836 \times 10^{-5}$ \\
\hline
\end{tabular}
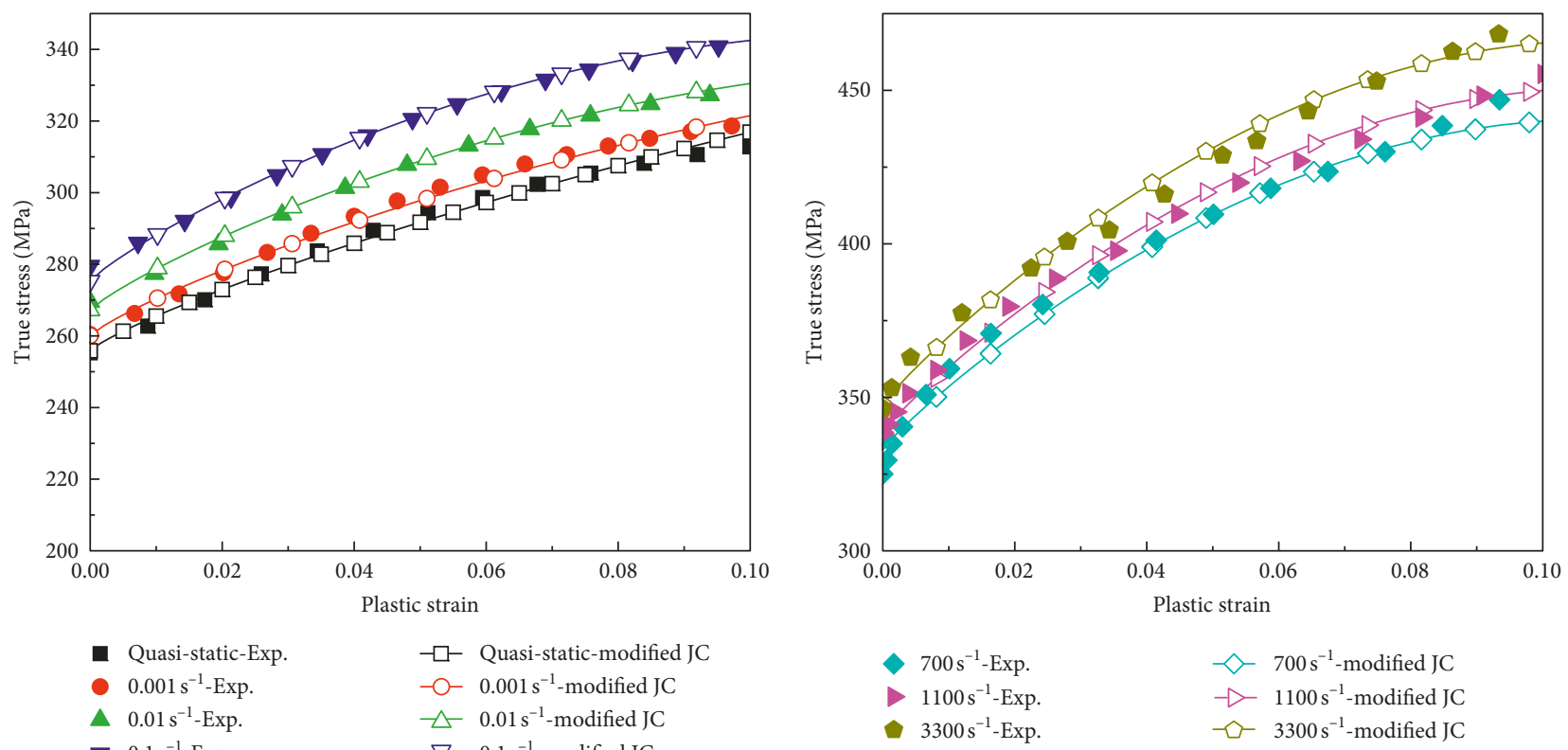

Quasi-static-Exp.

$0.001 \mathrm{~s}^{-1}$-Exp.

$-\square-$ Quasi-static-modified JC

$-0-0.001 \mathrm{~s}^{-1}$-modified JC

$\triangle 0.01 \mathrm{~s}^{-1}$-modified JC

$\nabla 0.1 \mathrm{~s}^{-1}$-Exp. $\rightarrow-0.1 \mathrm{~s}^{-1}$-modified JC

(a)

(b)

Figure 11: Comparison between the predicted results and experimented results: (a) low strain rates and (b) high strain rates.

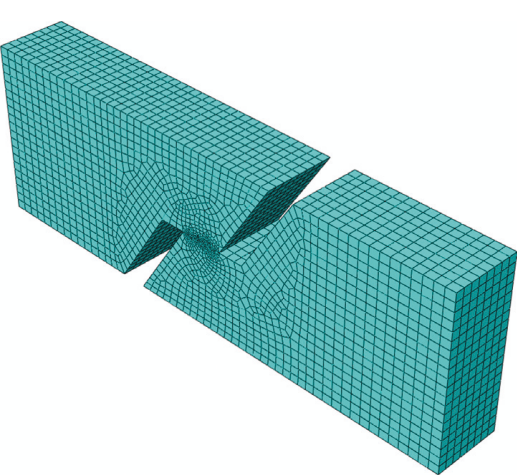

(a)

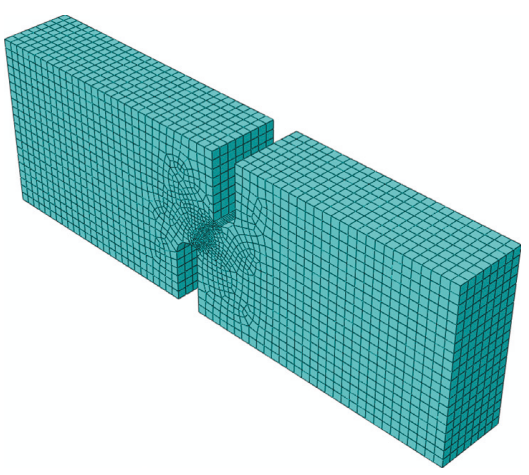

(d)

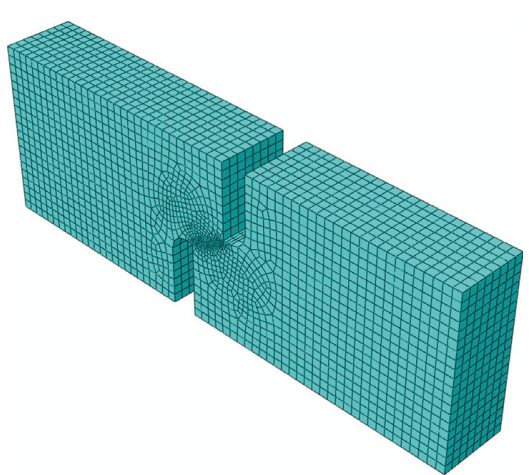

(b)

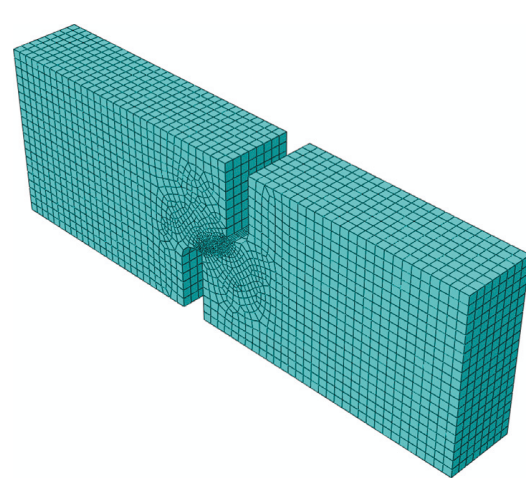

(c)

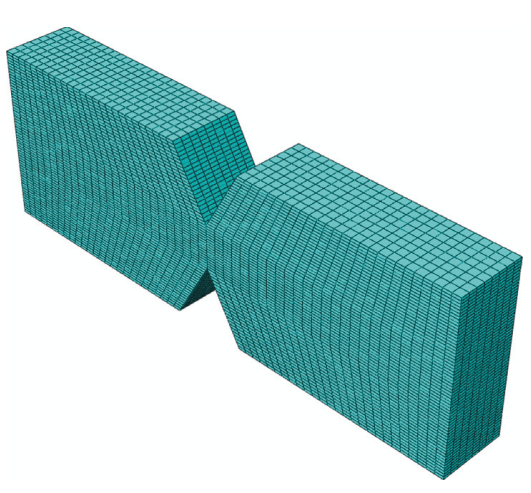

(e)

Figure 12: The 3D finite element model meshes of (a) $0^{\circ}$, (b) $30^{\circ}$, (c) $45^{\circ}$, (d) $60^{\circ}$, and (e) $90^{\circ}$ specimens. 


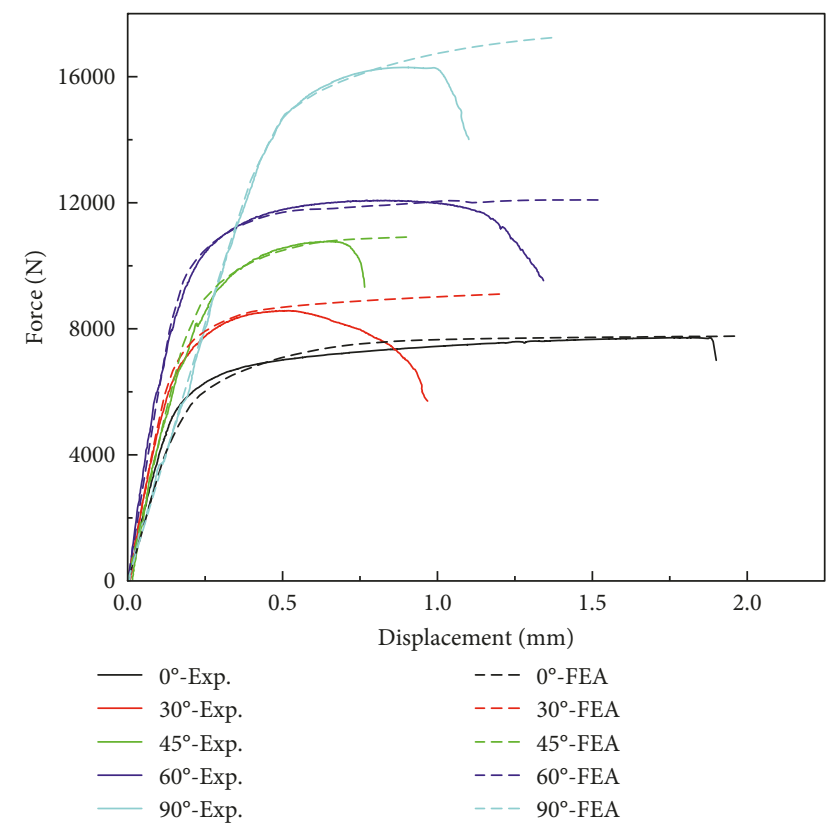

Figure 13: Comparison between numerical simulations and experiments.

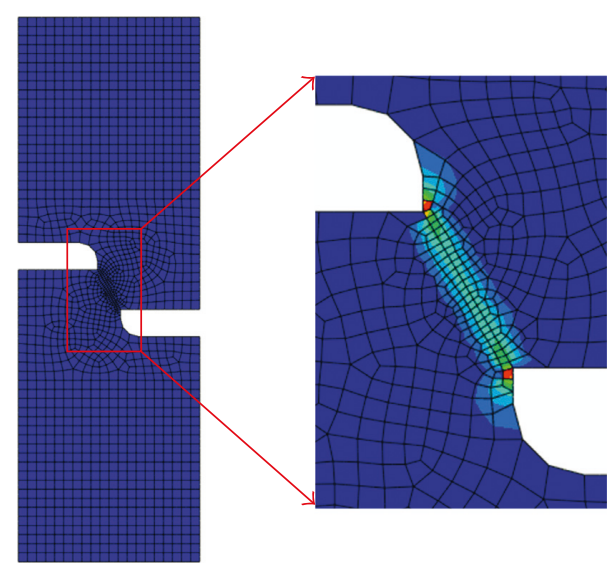

FIgURE 14: The distribution of equivalent plastic strain at the fracture time step in a typical numerical simulation.

$$
\begin{aligned}
R & =\frac{\sum_{i=1}^{N}\left(E_{i}-\bar{E}\right)\left(P_{i}-\bar{P}\right)}{\sqrt{\sum_{i=1}^{N}\left(E_{i}-\bar{E}\right)^{2}\left(P_{i}-\bar{P}\right)}}, \\
\mathrm{NMBE} & =\frac{\sum_{i=1}^{N}\left(E_{i}-P_{i}\right)}{\sum_{i=1}^{N} E_{i}}, \\
\mathrm{AARE} & =\frac{1}{N} \sum_{i=1}^{N}\left|\frac{E_{i}-P_{i}}{E_{i}}\right| \times 100 \%,
\end{aligned}
$$

where $E_{i}$ and $P_{i}$ are the experimental and predicted values, while $\bar{E}$ and $\bar{P}$ are the mean values of them, respectively. $N$ is the total number of data used in this study. The correlation coefficient is used to characterize the degree of a linear correlation relationship between two variables. The NMBE represents the mean bias value of predicted
TABLE 7: The calculated and actual initial stress triaxialities and corresponding fracture strains.

\begin{tabular}{lccccc}
\hline$\alpha$ & $0^{\circ}$ & $30^{\circ}$ & $45^{\circ}$ & $60^{\circ}$ & $90^{\circ}$ \\
\hline$\sigma_{\text {cal }}^{*}$ & 0 & 0.105 & 0.167 & 0.236 & 0.33 \\
$\sigma_{\text {sim }}^{*}$ & 0.04 & 0.159 & 0.221 & 0.369 & 0.741 \\
$\varepsilon_{p}^{f}$ & 0.767 & 0.948 & 1.140 & 1.423 & 0.732 \\
\hline
\end{tabular}

$\sigma_{\text {cal }}^{*}$ : the initial stress triaxiality calculated with $(8) ; \sigma_{\text {sim }}^{*}$ : the initial stress triaxiality obtained from the numerical simulations.

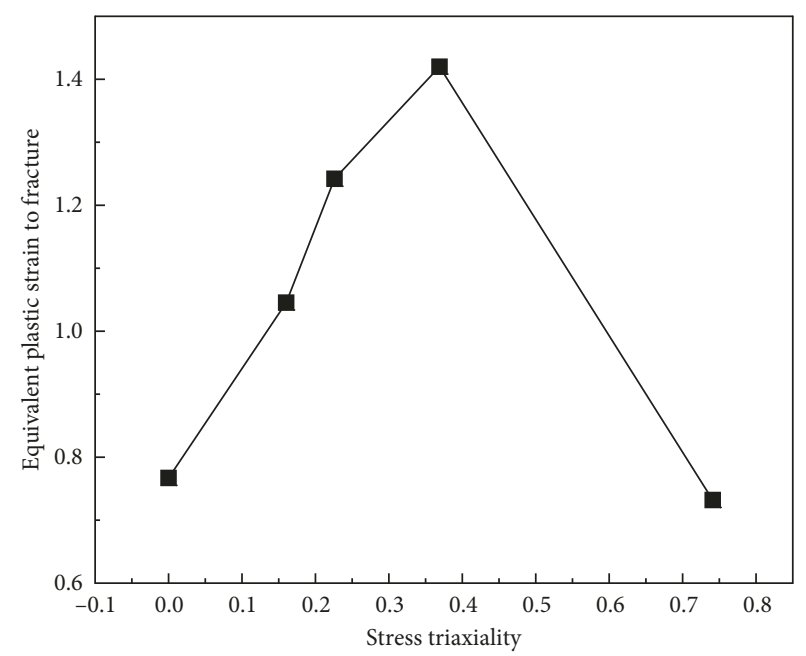

FIgURE 15: Actual initial stress triaxialities coupled with equivalent plastic strains to fracture.

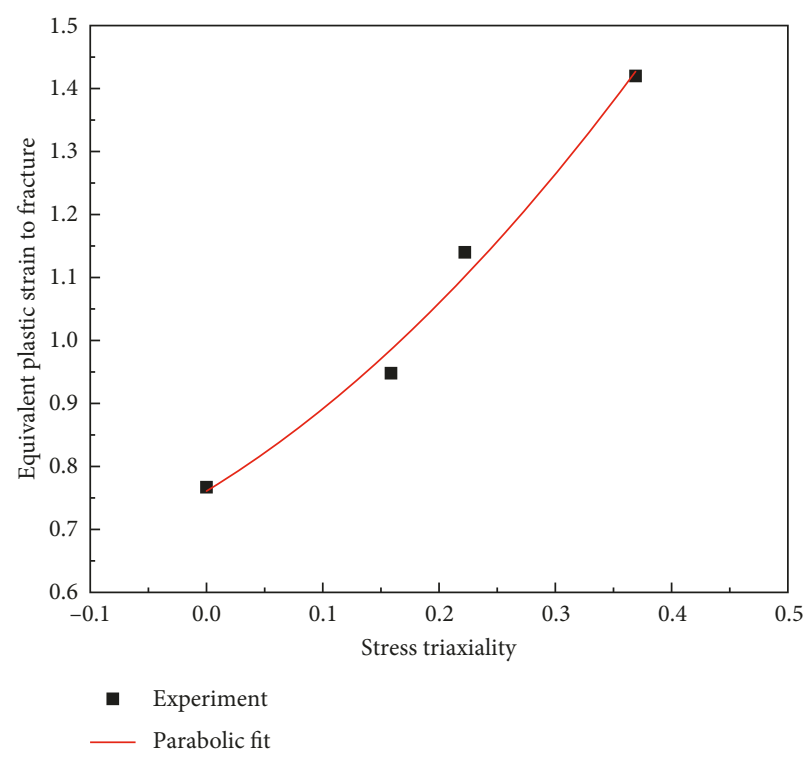

FIgURE 16: Parabolic fitting for low triaxialities.

values, and a positive NMBE value means overprediction, while negative one means underprediction from a model. AARE is an unbiased statistic that estimates the accuracy of predictions by comparing the relative error term by term. 


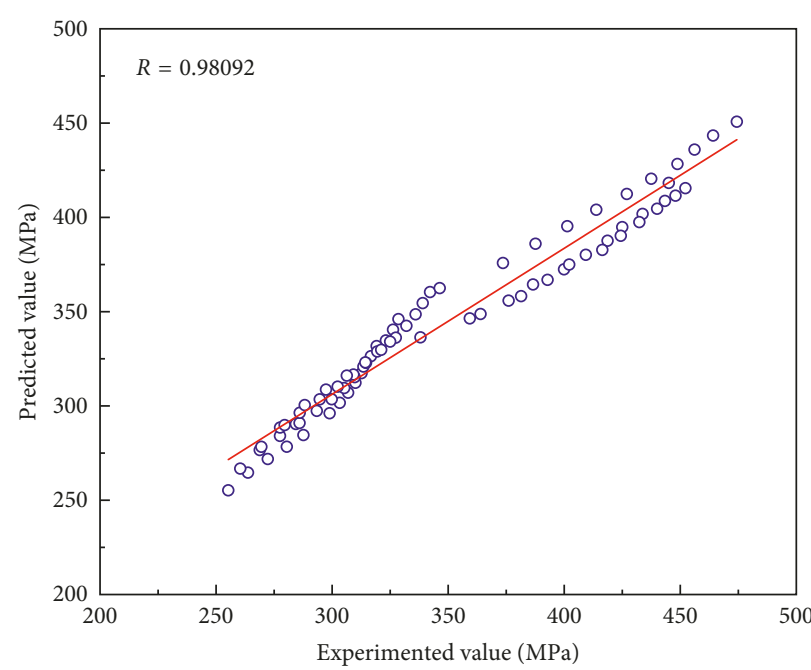

(a)

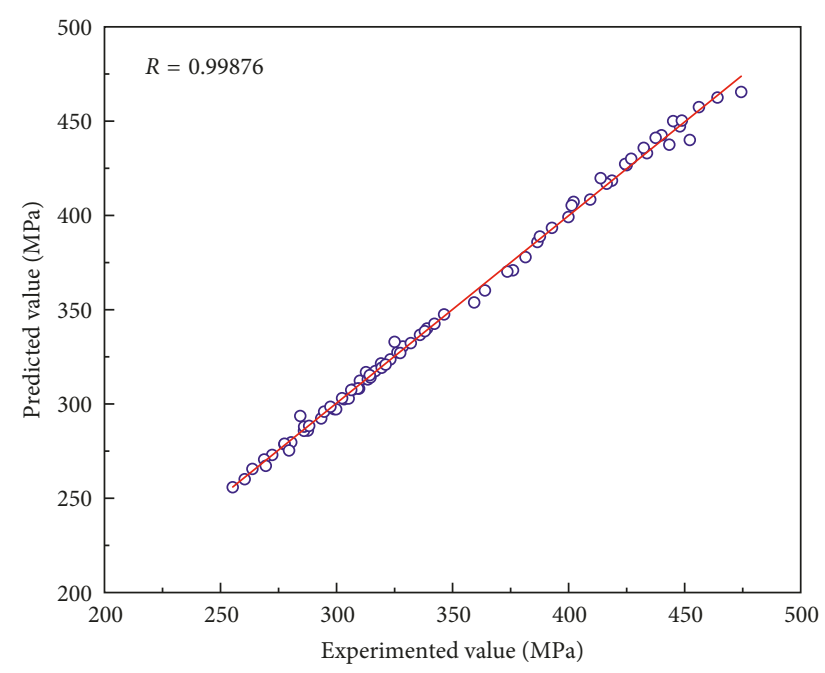

(b)

FIGURE 17: Correlation analysis between experimental values and predicted values: (a) the original JC model and (b) the modified JC model.

Experimental values of flow stress and corresponding predicted values obtained from the original JC model as well as modified JC model are plotted in the coordinate system as shown in Figure 17. It is can be seen that the data points for the modified JC model are more close to the best line compared with the original one. The comparison indicates that the predicted values of the modified JC model correlate with experimental values better than the original JC model.

The performance of the original Johnson-Cook model and modified Johnson-Cook model is shown in Table 8. The average absolute relative errors of the original JC model and modified JC model are $3.71 \%$ and $1.34 \%$, while the normalized mean bias errors are $6.8 \%$ and $-0.049 \%$, respectively. These results show that the modified JC model features higher prediction accuracy than the original JC model.

In addition, the absolute relative error is employed to analyze the performance of the two models. The absolute relative error can be calculated with the following equation:

$$
\text { Absolute relative error }=\left|\frac{E_{i}-P_{i}}{E_{i}}\right| \times 100 \% .
$$

It can be obtained that the absolute relative error given by the original JC model varies from $0.0031 \%$ to $8.14 \%$, while the value is in the range of $0.05 \%$ to $3.26 \%$ for the modified JC model. The distribution of the absolute relative errors is plotted in Figure 18. For almost 95\% data sets, the relative error of the modified JC model is concentrated in the range of 0 to $2 \%$, while the relative error scatters from 0 to $9 \%$ erratically for the original JC model. In conclusion, the modified Johnson-Cook model can describe the flow behavior of 6005 aluminum alloy more accurately than the original Johnson-Cook model.

4.2. The Fracture Behavior under Low Stress Triaxiality. In this paper, a parabolic equation is established to determine the fracture strain, in which stress triaxiality is the only independent variable. Several studies $[10,23,24]$ have
TABLE 8: The performance of the two models.

\begin{tabular}{lccc}
\hline Indicator & $R$ & AARE (\%) & NMBE (\%) \\
\hline Original JC & 0.9809 & 3.71 & 6.80 \\
Modified JC & 0.9987 & 1.34 & -0.049 \\
\hline
\end{tabular}

investigated the fracture behavior of aluminum alloy, while most of them focus on the high stress triaxiality. The Johnson-Cook fracture model is the most commonly used failure criterion. Bao and Wierzbicki [23] have studied the fracture ductility of AA2024-T351 in the entire range of stress triaxialities $(-1 / 3$ to 0.95$)$. Three expressions were given for negative $(-1 / 3$ to 0$)$, low $(0-0.4)$, and high (0.4-0.95) triaxialities, respectively. A similar tendency of fracture strain is observed for AA6005 in the range from 0.04 to 0.741 .

With an elongation beyond 10\%, $6005 \mathrm{Al}$ alloy can be regarded as a ductile material. To further investigate the fracture mode of $6005 \mathrm{Al}$ alloy during tensile, pure shear, and tensile-shear combined tests, some magnified fracture surfaces are collected by a scanning electron microscope (SEM). Figure 19 shows the typical fracture surfaces of tensile shearing specimens with the notch degree from $0^{\circ}$ to $90^{\circ}$. Figure 19(a) shows the pure shearing fracture surface, where there are typical "ripple waves" and the direction of the shear fracture surface is parallel to that of the maximum shear stress. It indicates that the fracture mechanism is shear fracture. During the pure shear test, the stress triaxiality is about zero. The shear band appears in the center of the specimen. Cracks are produced within the shear band and then coalesced. When the equivalent plastic strain reaches the critical value, the fracture takes place. Figure 19(e) shows the fracture surface of $90^{\circ}$ specimen, where there exist a number of dimples with different size. During the tensile test on $90^{\circ}$ specimen, there is a high stress triaxiality in the root of the notch. The specimen fractures after experiencing the process of nucleation, growth, and coalescence of voids. For tensile shearing tests, dimple and shear combination of different degrees can be seen in Figures 19(b)-(19d). In the 


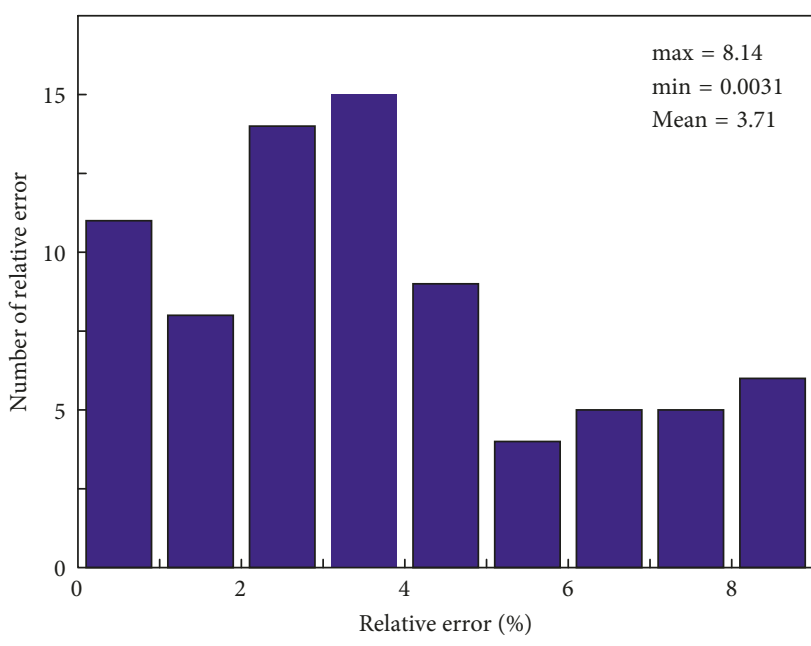

(a)

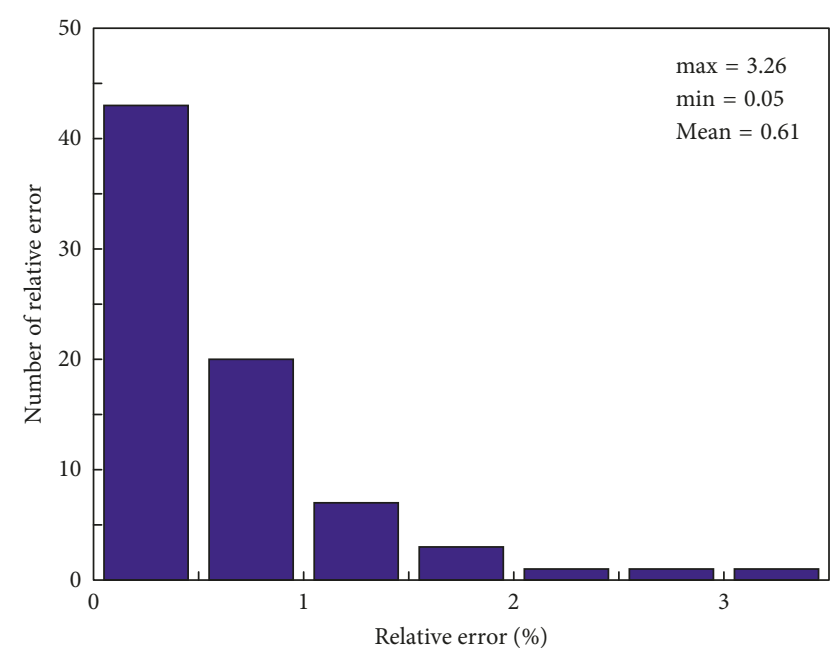

(b)

FIGURE 18: The distribution of the absolute relative errors of (a) the original JC model and (b) modified JC model.

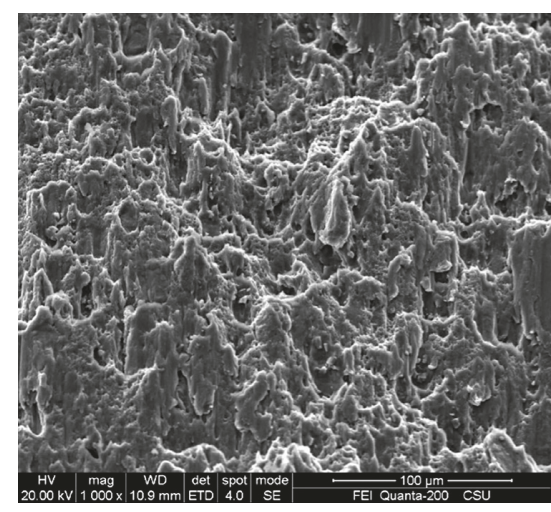

(a)

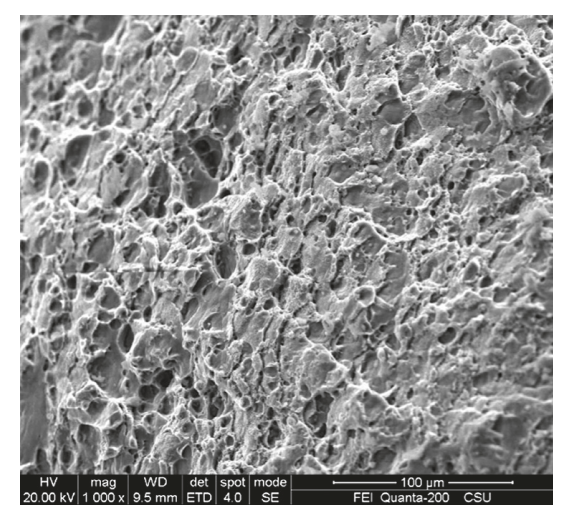

(b)

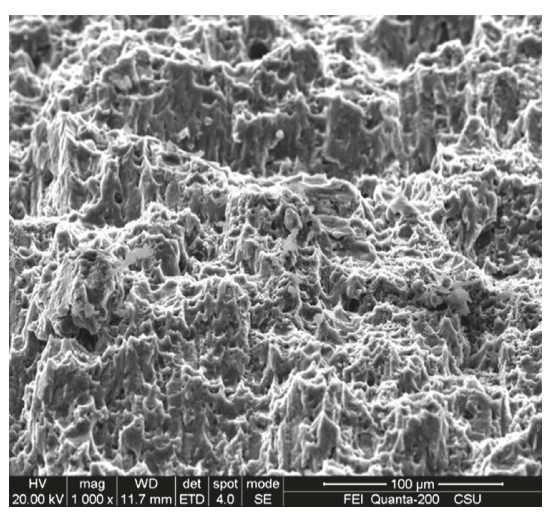

(c)

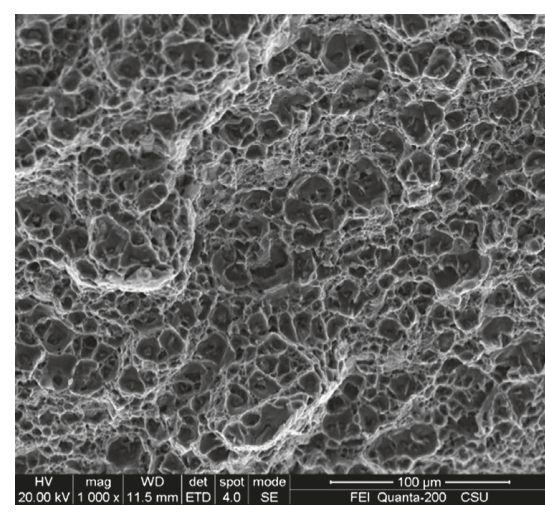

(d)

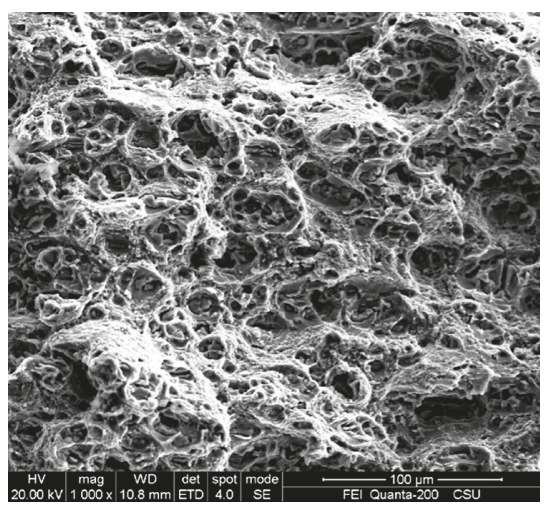

(e)

Figure 19: Fracture surfaces of (a) $0^{\circ}$, (b) $30^{\circ}$, (c) $45^{\circ}$, (d) $60^{\circ}$, and (e) $90^{\circ}$ notch specimens.

range of low stress triaxialities, fracture is caused by a combined function of shear and void growth.

\section{Conclusion}

In this study, the dynamic constitutive behavior of $6005 \mathrm{Al}$ alloy is investigated by means of experiments and numerical simulations. Tensile tests under different strain rates indicate that the flow stress of the investigated material is rather sensitive to strain rate. What is more, a clear effect of strain hardening is observed. Based on the tensile test data, a simplified Johnson-Cook model was established to describe the flow stress of $6005 \mathrm{Al}$ alloy at various strain rates. Furthermore, the original JC model was modified using the 
$C$ function. The modified JC model is proved to be effective in predicting the flow stress of $6005 \mathrm{Al}$ alloy.

A set of tensile shearing tests were carried out to study the fracture behavior under low stress triaxialities. $\mathrm{Nu}$ merical simulations based on FEA were used to obtain the actual initial stress triaxialities and equivalent plastic strain to fracture. The tendency of the fracture strain is nonmonotonic in the triaxiality range of 0.04 to 0.74 . A parabolic fracture criterion was thus proposed in the triaxiality range of 0.04 to 0.369 . Finally, the fractography analysis for $6005 \mathrm{Al}$ alloy indicates that the material has a typical ductile fracture mechanism including the shear fracture under pure shear and the dimple fracture under uniaxial tensile.

\section{Conflicts of Interest}

The authors declare that there are no conflicts of interest regarding the publication of this paper.

\section{Acknowledgments}

The authors thank Modern Analysis and Testing Center of Central South University for experimental assistance in performing the mechanical tests and electron microscope scan experiment. This work was supported by the National Natural Science Foundation of China (nos. 51405517 and U1334208) and the Natural Science Foundation of Hunan (no. 2015JJ3155).

\section{References}

[1] I. N. Fridlyander, V. G. Sister, O. E. Grushko, V. V. Berstenev, L. M. Sheveleva, and L. A. Ivanova, "Aluminum alloys: promising materials in the automotive industry," Metal Science and Heat Treatment, vol. 44, no. 10, pp. 365-370, 2002.

[2] W. Brocker and R. D. Rosenberger, "Light weight potentials in coach body structures of high-speed trains," in Proceedings of WCRR, vol. 97, pp. 713-721, Florence, Italy, November 1997.

[3] Z. Lu, B. Li, C. Yang et al., "Numerical and experimental study on the design strategy of a new collapse zone structure for railway vehicles," International Journal of Crashworthiness, vol. 22, no. 5, pp. 1-15, 2017.

[4] J. Yan, S. Yao, P. Xu, Y. Peng, H. Shao, and S. Zhao, "Theoretical prediction and numerical studies of expanding circular tubes as energy absorbers," International Journal of Mechanical Sciences, vol. 105, pp. 206-214, 2015.

[5] P. Xu, C. Yang, Y. Peng, S. Yao, D. Zhang, and B. Li, "Crash performance and multi-objective optimization of a gradual energy-absorbing structure for subway vehicles," International Journal of Mechanical Sciences, vol. 107, pp. 1-12, 2016.

[6] Y. Peng, X. Wang, X. Xiong, and P. Xu, "Crashing analysis and multi-objective optimisation of duplex energy-absorbing structure for subway vehicle," International Journal of Crashworthiness, vol. 21, no. 4, pp. 338-352, 2016.

[7] Y. Peng, S. Wang, S. Yao, and P. Xu, "Crashworthiness analysis and optimization of a cutting-style energy absorbing structure for subway vehicles," Thin-Walled Structures, vol. 120, pp. 225-235, 2017.

[8] G. Liu, J. Xie, and S. Xie, "Experimental and numerical investigations of a new U-shaped thin plate energy absorber subjected to bending and friction," Thin-Walled Structures, vol. 115, pp. 215-224, 2017.

[9] S. M. Mirfalah-nasiri, A. Basti, and R. Hashemi, "Forming limit curves analysis of aluminum alloy considering the through-thickness normal stress, anisotropic yield functions and strain rate," International Journal of Mechanical Sciences, vol. 117, pp. 93-101, 2016.

[10] G. Haugou, E. Markiewicz, J. Fabis, and G. Gary, "Contribution to the definition of a partial overlapping plastic strain rates domain for moderate loadings-application to tensile testing on metallic materials," International Journal of Crashworthiness, vol. 9, no. 2, pp. 187-194, 2004.

[11] X. Chen, Y. Peng, S. Peng, S. Yao, C. Chen, and P. Xu, "Flow and fracture behavior of aluminum alloy 6082-T6 at different tensile strain rates and triaxialities," PLoS One, vol. 12, no. 7, article e0181983, 2017.

[12] F. Delannay, T. Pardoen, D. Lassance, and D. Fabre, "Micromechanics of room and high temperature fracture in $6 \times x x \mathrm{Al}$ alloys," Progress in Materials Science, vol. 52, no. 1, pp. 62-129, 2007.

[13] B. Milkereit, N. Wanderka, C. Schick, and O. Kessler, "Continuous cooling precipitation diagrams of $\mathrm{Al}-\mathrm{Mg}-\mathrm{Si}$ alloys," Materials Science and Engineering: A, vol. 550, pp. 87-96, 2012.

[14] W. Yang, L. Huang, R. Zhang, M. Wang, Z. Li, and Y. Jia, "Electron microscopy studies of the age-hardening behaviors in 6005A alloy and microstructural characterizations of precipitates," Journal of Alloys and Compounds, vol. 514, pp. 220-233, 2012.

[15] O. S. Lee, H. Choi, and H. Kim, "High-temperature dynamic deformation of aluminum alloys using SHPB," Journal of Mechanical Science and Technology, vol. 25, no. 1, pp. 143-148, 2011.

[16] H. Ying, X. Feng, J. Ying, and J. Jiao, "A modified Johnson Cook model for elevated temperature flow behavior of T24 steel," Materials Science and Engineering: A, vol. 577, pp. 138-146, 2013.

[17] L. Berkovic, A. Chabotier, F. Coghe, and L. Rabet, "Measuring and modeling of low temperature Hopkinson tests," Procedia Engineering, vol. 10, pp. 1645-1650, 2011.

[18] G. T. Gray, S. R. Chen, and K. S. Vecchio, "Influence of grain size on the constitutive response and substructure evolution of MONEL 400," Metallurgical and Materials Transactions A, vol. 30, no. 5, pp. 1235-1247, 1999.

[19] K. Y. Huh and A. D. Gosman, "A phenomenological model of diesel spray atomization," in Proceedings of the International Conference on Multiphase Flows, Tsukuba, Japan, September 1991.

[20] M. A. Mccarthy, J. R. Xiao, and C. T. Mccarthy, "Modelling of bird strike on an aircraft wing leading edge made from fibre metal laminates-part 2," Applied Composite Materials, vol. 11, no. 5, pp. 317-340, 2004.

[21] J. Qin, R. Chen, X. Wen, Y. Lin, M. Liang, and F. Lu, "Mechanical behaviour of dual-phase high-strength steel under high strain rate tensile loading," Materials Science and Engineering: A, vol. 586, pp. 62-70, 2013.

[22] G. R. Johnson and W. H. Cook, "A constitutive model and data for metals subjected to large strains, high strain rates and high temperatures," in 7th International Symposium on Ballistic, pp. 541-547, Hague, Netherlands, April 1983.

[23] Y. Bao and T. Wierzbicki, "On fracture locus in the equivalent strain and stress triaxiality space," International Journal of Mechanical Sciences, vol. 46, no. 1, pp. 81-98, 2004.

[24] B. Liu, R. Villavicencio, and C. Guedes Soares, "Experimental and numerical plastic response and failure of pre-notched transversely impacted beams," International Journal of Mechanical Sciences, vol. 77, pp. 314-332, 2013.

[25] G. R. Johnson and W. H. Cook, "Fracture characteristic of three metals subjected to various strains, strain rates, 
temperatures and pressures," Engineering Fracture Mechanics, vol. 21, pp. 31-48, 1985.

[26] A. L. Gurson, "Continuum theory of ductile rupture by void nucleation and growth: part I-yield criteria and flow rules for porous ductile media," Journal of Engineering Materials and Technology, vol. 99, no. 1, pp. 297-300, 1977.

[27] Y. Bao and T. A. Wierzbicki, "Comparative study on various ductile crack formation criteria," Journal of Engineering Materials and Technology, vol. 126, no. 3, pp. 314-324, 2004.

[28] T. Wierzbicki, Y. Bao, Y. W. Lee, and Y. Bai, "Calibration and evaluation of seven fracture models," International Journal of Mechanical Sciences, vol. 47, no. 4-5, pp. 719-743, 2005.

[29] Y. Bao and T. A. Wierzbicki, "Application of extended MohrCoulomb criterion to ductile fracture," International Journal of Fracture, vol. 161, no. 1, pp. 1-20, 2010.

[30] A. Gilioli, A. Manes, M. Giglio, and T. Wierzbicki, "Predicting ballistic impact failure of aluminium 6061-T6 with the rateindependent Bao-Wierzbicki fracture model," International Journal of Impact Engineering, vol. 76, pp. 207-220, 2015.

[31] F. Feng, S. Huang, Z. Meng et al., "Experimental study on tensile property of AZ31B magnesium alloy at different high strain rates and temperatures," Materials \& Design, vol. 57, pp. 10-20, 2014.

[32] Y. C. Lin, X. M. Chen, and G. Liu, "A modified Johnson-Cook model for tensile behaviors of typical high-strength alloy steel," Materials Science and Engineering: A, vol. 527, no. 26, pp. 69806986, 2010.

[33] T. Børvik, A. H. Clausen, M. Eriksson, T. Berstad, O. Sture Hopperstad, and M. Langseth, "Experimental and numerical study on the perforation of AA6005-T6 panels," International Journal of Impact Engineering, vol. 32, no. 1-4, pp. 35-64, 2006.

[34] J. Q. Tan, M. Zhan, S. Liu, T. Huang, J. Guo, and H. Yang, "A modified Johnson-Cook model for tensile flow behaviors of 7050-T7451 aluminum alloy at high strain rates," Materials Science and Engineering: A, vol. 631, pp. 214-219, 2015. 


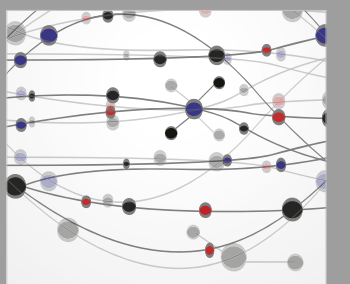

The Scientific World Journal
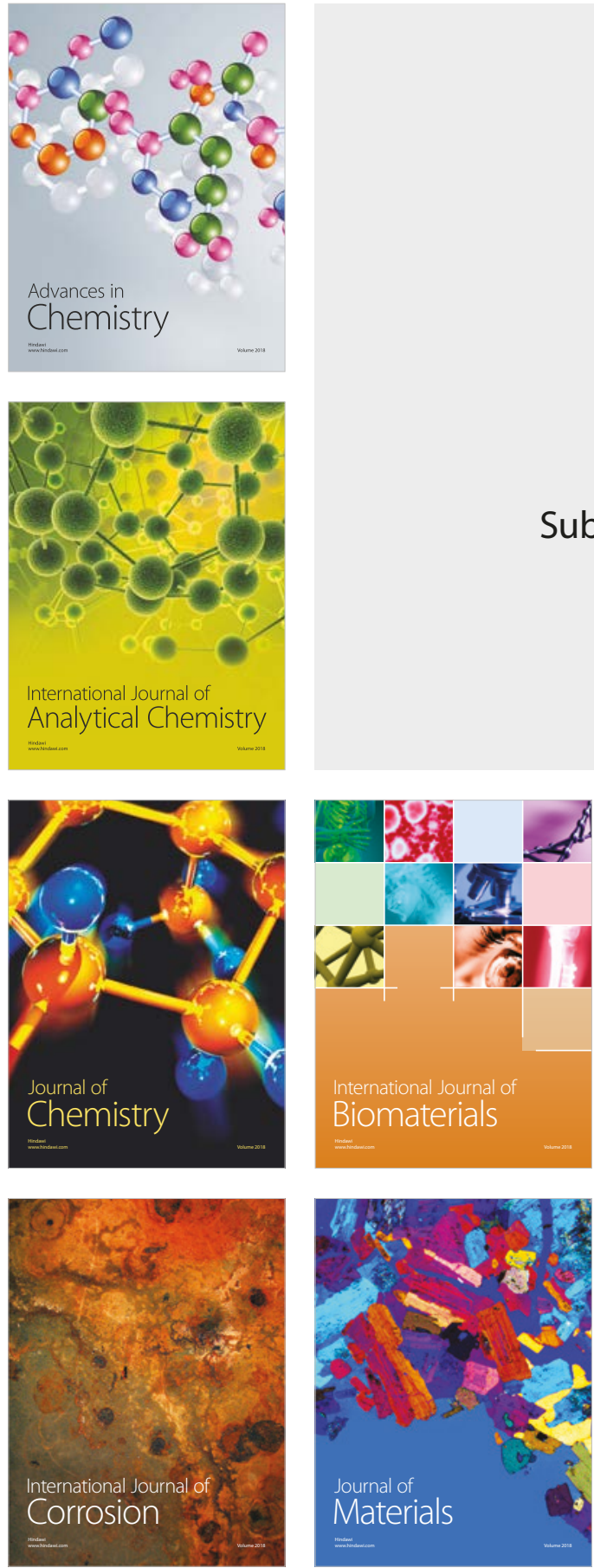

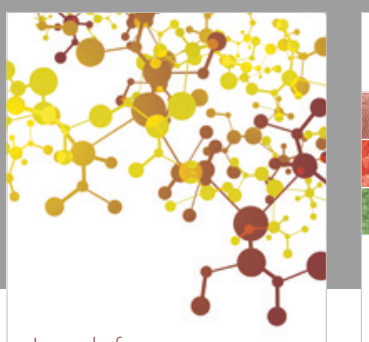

Journal of

Applied Chemistry
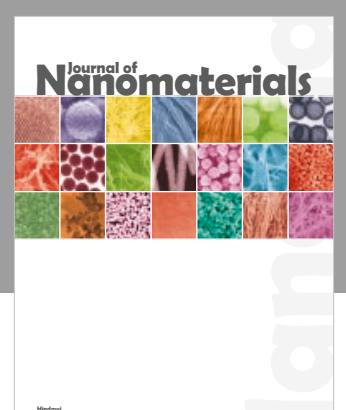

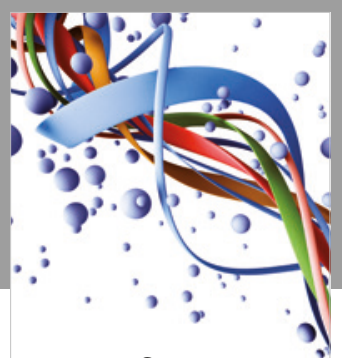

Scientifica

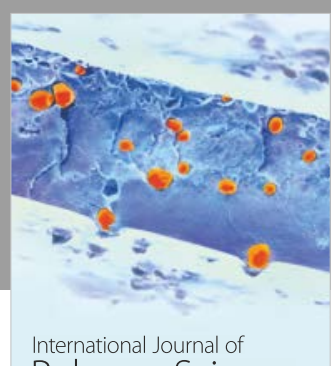

Polymer Science

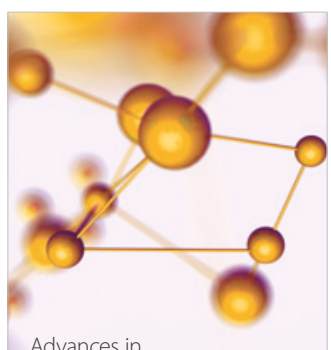

Physical Chemistry
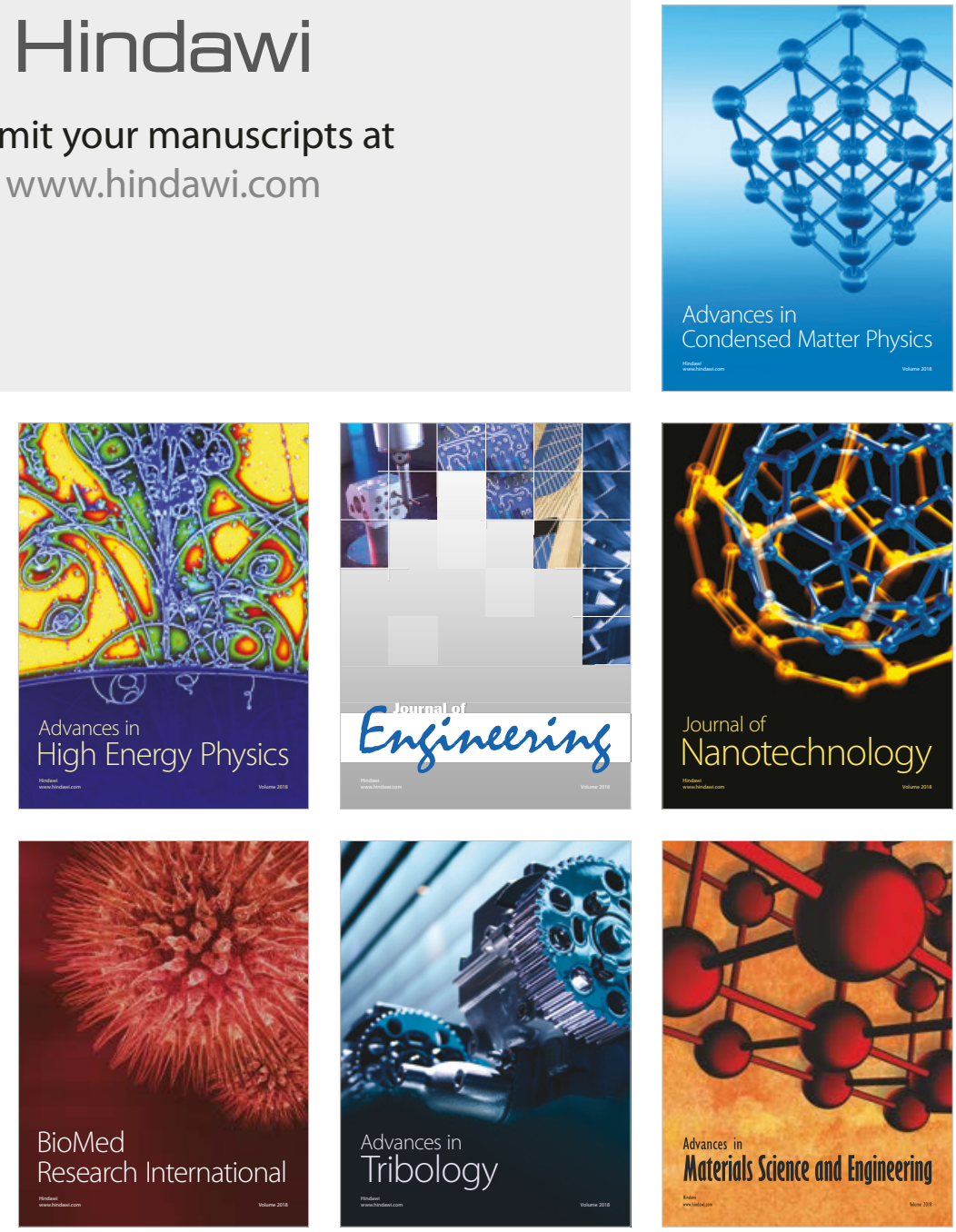